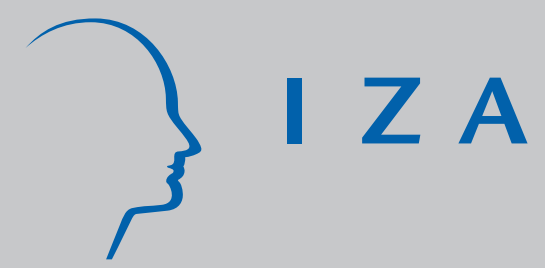

IZA DP No. 9979

Grandparental Availability for Child Care and Maternal Employment:

Pension Reform Evidence from Italy

Massimiliano Bratti

Tommaso Frattini

Francesco Scervini

June 2016 


\title{
Grandparental Availability for Child Care and Maternal Employment: Pension Reform Evidence from Italy
}

\author{
Massimiliano Bratti \\ University of Milan, IZA and LdA \\ Tommaso Frattini \\ University of Milan, CReAM, IZA, LdA and Dondena Centre \\ Francesco Scervini \\ HDCP-IRC, IUSS Pavia \\ Discussion Paper No. 9979 \\ June 2016 \\ IZA \\ P.O. Box 7240 \\ 53072 Bonn \\ Germany \\ Phone: +49-228-3894-0 \\ Fax: +49-228-3894-180 \\ E-mail: iza@iza.org
}

\begin{abstract}
Any opinions expressed here are those of the author(s) and not those of IZA. Research published in this series may include views on policy, but the institute itself takes no institutional policy positions. The IZA research network is committed to the IZA Guiding Principles of Research Integrity.

The Institute for the Study of Labor (IZA) in Bonn is a local and virtual international research center and a place of communication between science, politics and business. IZA is an independent nonprofit organization supported by Deutsche Post Foundation. The center is associated with the University of Bonn and offers a stimulating research environment through its international network, workshops and conferences, data service, project support, research visits and doctoral program. IZA engages in (i) original and internationally competitive research in all fields of labor economics, (ii) development of policy concepts, and (iii) dissemination of research results and concepts to the interested public.
\end{abstract}

IZA Discussion Papers often represent preliminary work and are circulated to encourage discussion. Citation of such a paper should account for its provisional character. A revised version may be available directly from the author. 


\section{ABSTRACT \\ Grandparental Availability for Child Care and Maternal Employment: Pension Reform Evidence from Italy*}

In this paper, we exploit pension reform-induced changes in retirement eligibility requirements to assess the role of grandparental child care availability in the employment of women who have children under 15 . We focus on Italy for two reasons: first, it has low rates of female employment and little formal child care provision, and second, it has undergone several pension reforms in a relatively short time span. Our analysis shows that, among the women studied, those whose own mothers are retirement eligible have a 13 percent higher probability of being employed than those whose mothers are ineligible. The pension eligibility of maternal grandfathers and paternal grandparents, however, has no significant effect on the women's employment probability. We also demonstrate that the eligibility of maternal grandmothers mainly captures the effect of their availability for child care. Hence, pension reforms, by potentially robbing households of an important source of flexible, low-cost child care, could have unintended negative consequences for the employment rates of women with children.

JEL Classification: J13, J22

Keywords: $\quad$ grandparental child care, maternal employment, pension reform, retirement

Corresponding author:

Tommaso Frattini

Department of Economics, Management and Quantitative Methods

University of Milan

Via Conservatorio 7

20122 Milano

Italy

E-mail: tommaso.frattini@unimi.it

\footnotetext{
* This version benefited from comments received at the $30^{\text {th }}$ Annual Conference of the Italian Association of Labour Economists (AIEL, Cagliari); the ECSR, Collegio Carlo Alberto, and NASP Joint Spring School on "The quantitative analysis of ageing and its relation to social inequality;" the HALM Workshop "Household Economics in an Ageing Society" (Catholic University of Milan); Marche Polytechnic University; the University of Siena; and the University of Milan. We also received useful feedbacks from Erich Battistin, Federica Origo and Daniela Vuri, who are gratefully acknowledged. The usual disclaimers apply.
} 


\section{Introduction}

Given the progressive population aging in developed countries, increasing female labor force participation (hereafter, LFP) and employment are paramount if Europe is to meet its 2020 target of 75 percent employment among those aged 20-64, a necessary objective for boosting economic growth and ensuring national pension system sustainability. Achieving this goal involves narrowing the employment gender gap, which to different degrees is still substantial in all EU member states but especially high in Southern European countries. In fact, a recent OECD (2012) analysis of labor market gender gaps reports 2011 male versus female employment rates in the 15-64 age group of 65.9 versus 45.1 percent in Greece, 64.1 versus 52.8 percent in Spain, and 67.5 versus 46.5 percent in Italy.

Although several explanations are proposed for the low labor force attachment of women in Southern European countries, the most cited are cultural influences like the "male breadwinner model" and institutional constraints. Among the latter, the lack of publicly provided child care is stressed as a major barrier to women's reconciliation of family with career (Del Boca and Sauer 2009). In Italy, for instance, public expenditure on child care accounts for a tiny 0.2 percent of GDP, which is half of the average OECD-30 expenditure (see Figure 1). Unfortunately, the need to cope with tight budgetary constraints after the Great Recession has prevented most Southern European countries from increasing the funds allocated to family policies and thus prevented any substantial progress in raising female employment. It is therefore likely that in a context of low or even shrinking public child care provision, grandparents (and relatives in general) may serve as an important source of affordable child care for working women. For instance, Hank and Buber (2009) show that about 32 percent of European grandmothers are engaged in regular child care (i.e., almost weekly or more often) with percentages in countries such as Greece, Italy, and Spain almost twice as large as those in Scandinavia.

In this paper, we assess whether grandparents’ potential availability for child care, proxied by their meeting pension eligibility requirements, has a positive effect on female, and especially 
maternal, employment. ${ }^{1}$ This question is relevant not only in light of the widespread structural underinvestment in public child care in many European countries, but also the recent pension reforms introduced in many EU member states. These reforms, by setting stricter retirement eligibility requirements such as a higher retirement age, may have unintended consequences on female employment. For example, we show that a raised retirement age, by reducing the supply of low cost, flexible, informal child care provided by grandparents, can reduce the employment of mothers. Hence, pension reforms that are not coupled with sufficient investment in public child care may further exacerbate the already wide intergenerational and gender gaps in employment by reducing the employment of young women relative not only to older women but also to young men, who traditionally bear less of the child care burden.

The case of Italy is ideal for studying how changes in pension eligibility impact employment rates because in recent years it has undergone several pension reforms that have gradually increased retirement requirements. For instance, whereas prior to 1992, the 20-year accumulated contribution rule allowed many public sector workers to retire in their 40s or early 50s, since then several pension reforms have gradually raised the age requirement to 65. These pension eligibility rules, which vary over time and according to such factors as gender and employment sector, provide an arguably exogenous variation (see also, Bottazzi et al. 2006, Battistin et al. 2009, 2015, AparicioFenoll and Vidal-Fernandez 2015) used in this paper to identify the effect of grandparental child care availability on maternal employment.

Our estimates show that mothers of cohabiting children under 15 whose own mothers are eligible for retirement have a 7.8 percentage point higher probability of employment (+13 percent) than those whose mothers are not yet eligible. We interpret this result to mean that grandparental availability for child care facilitates the labor participation of women with young children. This

\footnotetext{
${ }^{1}$ In this paper, we use the term "women" to refer to the females whose employment or labor force status is being investigated. Although both parents and parents-in-law are sometimes collectively referred to as "grandparents," (adopting the perspective of the women's children), the women's "mother" and "father" are specifically designated as "maternal grandmother" and "maternal grandfather," respectively, while the "mother-in-law" and "father-in-law" are labeled "paternal grandmother” and "paternal grandfather."
} 
interpretation is confirmed by the absence of any such effect for women who have no cohabiting children under 15 or for men, and by the larger magnitude of the effect for women with very young children, whose child care needs are most intensive.

The remainder of the paper is organized as follows. Section II briefly reviews the most relevant literature on the effect of grandparents' availability and child care supply on LFP and employment, and highlights our main contributions. Section III gives a brief history of the Italian pension laws, whose nature assures exogenous variation in grandparental availability for child care, and describes our empirical strategy. Section IV describes the data used in our empirical analysis, and Section V investigates the relation between pension eligibility and retirement status. Section VI reports our primary analytical results and the outcomes of several robustness checks. Section VII then presents some back-of-the-envelope calculations of the potential effect of pension laws on maternal aggregate employment. Section VIII summarizes the main findings and concludes the paper.

\section{Relevant Literature}

Extant studies on the effect of informal grandparent-provided child care on women's labor market outcomes differ greatly in both the variables used to measure grandparental child care and the identification strategies adopted. A few studies are based on surveys that provide information on the actual use of grandparental child care. Arpino et al. (2014) employ data from the 2003 wave of the Italian National Statistical Institute’s (ISTAT) multipurpose “Family and Social Subjects Survey” (FSSS), which collects information on a mother's use of grandparental child care. By instrumenting the latter with grandparents being alive or not, these authors estimate that using grandparent-provided child care raises a mother's likelihood of being in the labor market by 32.3 percentage points. As the authors stress, however, one important assumption for identifying a causal impact (in addition to the exogeneity of grandparents' being alive) is that living grandparents affect female labor market outcomes only via their provision of child care. This exclusion restriction 
assumption, however, could fail for multiple reasons, including early loss of a parent or parent-inlaw that changes the amount and timing of intervivo transfers or bequests, as well as grandparental availability for child care, which would also affect women's LFP and employment. In earlier work, Posadas and Vidal-Fernandez (2013) use a similar identification strategy to demonstrate a positive effect on women's LFP in U.S. panel data. Their instrumental variables (IV, hereafter) estimates, however, are much lower (14.6 percentage points.) and less precise ( $p$-value $=0.29)$ than those reported by Arpino et al. (2014) for Italy, partly perhaps because of the two countries' different institutional settings. $^{2}$

Many surveys fail to gather information on women's use of grandparent-provided child care, reporting only that the grandparents are still alive. For instance, Del Boca (2002), using data from the Survey on Household Income and Wealth (SHIW), proxies informal child care availability by reports of at least one grandparent being alive, which she then links positively to maternal participation in Italy's labor force. For identification, she assumes that grandparent survival is not associated with the unobservable variables potentially affecting the mothers' labor market behaviors and outcomes. Her results are thus likely to underestimate the role of grandparental availability because some of the living grandparents may be unavailable for child care (e.g., still working, bad health, geographic distance).

Other studies come nearer to proxying grandparental availability by exploiting variations in their geographic proximity based on the assumption that the closer the grandparents live to their children or children-in-law, the more available they are for child care. In fact, Compton and Pollak (2014) do show that in the U.S., a woman's geographic proximity to her mother or mother-in-law raises the likelihood of her participating in the labor force by 4-10 percentage points. They interpret this finding as the effect of informal child care because the correlation is observable for women with young children but not for others whose labor supply is unlikely to respond to grandparental

\footnotetext{
${ }^{2}$ Based on their individual fixed effects estimates, which they deem the most reliable, Posadas and Vidal-Fernandez (2013) report that grandparental child care increases women’s LFP by 9 percentage points.
} 
availability, such as men and childless women. Nevertheless, even though having geographically close grandparents clearly measures grandparental availability more precisely than the simple fact of their being alive, it raises potential endogeneity and reverse causality issues related to the endogenous residential choices of both the women and their grandparents. Women who are more labor market oriented, for instance, may more greatly value living close to their parents and having a potential source of low cost child care. ${ }^{3}$ The same criticism is applicable to studies that examine the effect on women's labor market outcomes of grandparents residing with the family (Leibowitz et al. 1992, Ogawa and Ermisch 1996, Abendroth et al. 2012) without addressing this arrangement’s potential endogeneity. ${ }^{4}$

The above studies do not take into account that surviving grandparents may greatly differ in the amount of time they can devote to child care. Two recent papers acknowledge this by exploiting grandparents' differences in labor market status generated by changes in retirement eligibility rules. Aparicio-Fenoll and Vidal-Fernandez (2015) use pension eligibility as an identification source in three waves (1998, 2003, and 2009) of FSSS and investigate the effect of grandparents' pension eligibility on female fertility and LFP. Using a two-sample two-stage least squares estimator, they show that the maternal grandmother's LFP decreases her daughters' LFP by 21.4 percentage points in the whole sample but surprisingly has a lower effect (14 percentage points) for the restricted sample of women with children under 3, whose child care needs are presumably greater. The authors also estimate a reduced form model in which the grandmother's lack of pension eligibility is directly included in her daughter's LFP, producing -5.1 percentage point and -3.4 percentage point effects for the whole and restricted samples, respectively. Battistin et al. (2015) use the 2009 wave of FSSS and exploit the exogenous variation generated by pension reforms to show that grandparents’ retirement eligibility has a positive effect on female fertility. Discussing the potential

\footnotetext{
${ }^{3}$ Compton and Pollak (2014) address this endogeneity issue by using a sample of military wives whose husbands' locations are determined by the military. Although their estimates are very imprecise, they offer some evidence that military wives residing in their birth state are more likely to be in the labor force.

${ }^{4}$ Maurer-Fazio et al. (2011) address the endogeneity of co-resident grandparents using both geographic variables and the women and their partners' characteristics as instruments. They find that in China, daughters living with their parents or in-laws are 12 percentage points more likely to participate in the labor market.
} 
channels for this effect, they also explore the impact of grandparents' pension eligibility on employment. Their estimated effect ranges between 4 percentage points and 2.5 percentage points, is concentrated among women under 35, and decreases with a woman's age. Our work is closely related to both papers, but differs in several technical as well as substantive respects. For instance, unlike Aparicio-Fenoll and Vidal-Fernandez (2015), we do not only use old-age pension, but also seniority pension rules to define grandparents' pension eligibility. This is an improvement because seniority pension rules have historically been particularly generous in Italy, and allowed for early retirement, especially in some sectors (e.g., the public sector). Thus, considering only old-pension rules may underestimate eligibility. Unlike Battistin et al. (2015), we do not assume continuous working lives for grandparents when defining seniority pension eligibility (see Section V). Although this assumption is probably innocuous for grandfathers, it could lead to a substantial overestimate of grandmothers' eligibility owing to the relevant share of mothers experiencing career interruptions, or even permanently quitting employment, around childbearing (Pronzato 2009). ${ }^{5}$ Underestimation or overestimation of grandparents' eligibility (misclassification error) may lead to an attenuation bias in the estimates (Lewbel 2007). Additionally, Battistin et al. (2015) use retrospective data to reconstruct life-cycle labor supply, which, as the authors acknowledge, may be problematic for the analysis of labor market behavior because of the possibility of recall errors. By considering only information on mothers' current employment, we minimize the impact of recall bias. A further, more substantive difference from both Aparicio-Fenoll and Vidal-Fernandez (2015) and Battistin et al. (2015) is that we consider only the effect on the employment of mothers and not of all women, as they do. Both effects are of interest, and potentially different. Our study throws light on the effect that pension reforms raising retirement eligibility requirements may have on the employment of women who are already mothers, by depriving them of grandparent-provided child care. By contrast, the labor supply effect estimated by the previous papers is the average effect on

\footnotetext{
${ }^{5}$ Also problematic is neglecting employment sector and type and/or applying private sector rules to all grandmothers, since it leads to a less precise measure of retirement eligibility.
} 
the whole female population, made of mothers and non-mothers. The two effects may differ, for instance, because mothers could decrease employment in response to the loss of grandparental child care caused by pension reforms. By contrast, those women who postpone or reduce fertility because of the reforms (non-mothers) may increase their labor supply, ${ }^{6}$ with a total effect on women's employment which is ambiguous in sign. Further, as discussed more extensively in Section III, another important innovation with respect to both papers is that we include in the empirical analysis women with dead grandparents, and we also allow for differential effects on maternal work of grandparents who are available for child care because they never worked and of those who worked and are pension-eligible. ${ }^{7}$ As discussed in the following section, we expect these two "types" of grandparents to have very different effects on mothers' employment, a theoretical prediction which is indeed met by the data (see Section VI).

\section{Using Pension Reforms to Identify the Effect of Grandparental Child Care}

\section{A. A Brief History of Pension Reforms in Italy}

Three major reforms were implemented in Italy during the 1990s to control severe imbalances in the public pension system. Prior to 1992, both retirement requirement and benefit amounts were very generous, with private sector workers allowed to retire at 60 (55 for women) with at least 15 years of contributions (old-age pension) or after 35 years of contributions, independent of age (seniority pension). ${ }^{8}$ The amount of the benefit was based both on contributory years and earnings received during the last working years, with a private sector worker receiving 2 percent of the average earnings of the last five years before retirement for every year of contribution paid. The steep earning profiles of most workers resulted in very generous benefits, leading to a record 1992

\footnotetext{
${ }^{6}$ Some recent studies using presumably exogenous variation in motherhood or family size to estimate the "motherhood" or “child” penalty include, for instance, Bailey (2006), Cruces and Galiani (2007), Cristia (2008), and Càceres-Delpiano (2012).

${ }^{7}$ In both papers, the authors impute retirement eligibility status also to grandparents who have always been out of the labor force. As a robustness check, we present the estimates following the same procedure in Section VI.D.

${ }^{8}$ Requirements for public sector workers were even more generous (see Table 1).
} 
benefits/GDP ratio of 16 percent, which raised the issue of system sustainability and triggered changes in the retirement age and benefits of current and future workers.

In the more general framework of public deficit reduction, the first emergency attempt to balance the pension system budget was the so-called Amato reform (D.Lgs.503/1992), which gradually increased both age and contribution requirements by five years. Two years later, the Dini reform (L.724/1994 and L.335/1995) reorganized the system so substantially as to imply a transition from earnings-based to contribution-based benefit computation while decreasing the age requirement but increasing the contribution requirement. It also introduced and regulated a parallel (voluntary) private pension system, which, however, applied only to individuals starting their first job after 1995 or voluntarily opting for the new system. ${ }^{9}$ Finally, the Prodi reform (L.449/1997) modified the part of the Dini reform targeted at older workers, slightly increasing the age requirements and harmonizing the rules for public and private sector employees and self-employed workers.

Table 1 summarizes the minimum age and contribution requirements set by the different reforms for private employees, public employees, and self-employed workers, which we use in the paper to define individual eligibility for a state pension. ${ }^{10}$ As previously explained, workers had some discretion in choosing the requirements-benefits scheme, so for each of the three laws, we report the minimum requirements for every year (half-year for those enacted by July 1) according to gender and employment sector and type. The first column refers to the 1992 Amato reform; the second to the 1995 Dini reform for older workers, as modified by the 1997 Prodi reform; and the third to the 1995 Dini reform for the most recent cohorts of workers. These latter requirements are relevant because older individuals could opt for this system. To illustrate, before the 1992 Amato reform, a 62-year-old male working in the public sector with 30 years of contributions was pension eligible based on both age (60 for public sector workers) and seniority (20 years for public sector

\footnotetext{
${ }^{9}$ Only in 2012 (Fornero reform, D.L.201/2011) was the contribution-based system (partially) extended to all workers. This reform, however, is outside our period of analysis.

${ }^{10}$ Workers in certain sectors (e.g., arduous or hazardous jobs like mining or long-distance driving) might have different requirements, but we disregard these in our paper.
} 
workers). In 1993, after the Amato reform, an identical individual was eligible only for a seniority pension because the retirement age had been raised. After 1996, an individual with the same characteristics would have been ineligible based on age (Amato), contribution years (Dini-Prodi), or both (Dini). Hence, consistent with the opportunity to choose the requirement, we assume that workers are eligible for a state pension whenever they satisfy at least one of the three criteria.

\section{B. Empirical Strategy}

Although we also seek to reveal how grandparental child care determines mothers' employment status, our data contain no information on whether and how much time grandparents spend with their grandchildren (a variable that would anyway be endogenous to women's labor market outcomes). Therefore, rather than directly relating women's employment to grandparental child care, we correlate the mothers' employment with their parents' and in-laws' potential availability for child care by estimating a model of the following form:

$$
y_{i t}=\alpha+\sum_{k=1}^{4}\left(\beta_{1}^{k} N W_{i t}^{k}+\beta_{2}^{k} E L_{i t}^{k}+\beta_{3}^{k} N E L_{i t}^{k}\right)+X_{i t} \gamma^{\prime}+\tau_{r t}+u_{i t}
$$

where $y_{i t}$ is a dummy capturing whether woman $i$ is employed or not in year $t$. Our main variables of interest are the three dummy variables $N W_{i t}^{k}, E L_{i t}^{k}, N E L_{i t}^{k}$ which capture the potential availability for child care of each relative $k=1, \ldots 4$, when 1 and 2 are the woman's mother and mother-in-law, respectively, and 3 and 4, her father and father-in-law. More specifically, $N W_{i t}^{k}$ is equal to 1 if individual $k$ is alive and has never worked (i.e., has always been out of the labor force) and 0 otherwise, and $E L_{i t}^{k}\left(N E L_{i t}^{k}\right)$ is an indicator variable equal to 1 if individual $k$ is alive and (in)eligible for a state pension (based on the pension eligibility rules outlined in the previous subsection). If individual $k$ is not alive, all three variables take the value 0 . We also control for all time variant region-specific factors that might affect female employment by including region by 
year fixed effects $\left(\tau_{r t}\right)$, which, among other things, capture differences in the socioeconomic environment (e.g., unemployment) and public child care provision. Finally, $X_{i t}$ is a vector of individual-level variables that may also affect women's labor supply and employment, including age and education of individual $i$, and her parents and in-laws, partner's income and education, and size of the municipality of residence. In the most saturated version of the model, this vector also includes the grandparents' employment sector (private or public) and type (employee or selfemployed).

We exploit two sources of variation to identify the effect of interest: The first is crosssectional variation determined by differences in the grandparents' gender, education, and employment sector and type. These latter are generally associated with different ages of entry into the labor market (and thus years of pension contributions conditional on age), as well as different retirement ages even under the same laws (which tend to favor public employees and women). The second is time variation resulting from the pension rule changes introduced by the different reforms passed during our estimation period. In addition to estimating models that exploit each of these two variations, we also compute a more saturated model including all factors determining the grandparents' eligibility status, meaning that identification comes only from time variations in the reform-induced eligibility rules. This saturated model enables comparison of like with like; for example, women with parents and in-laws having exactly the same characteristics but whose retirement eligibility status varies because of the law in place at the time. It also controls for grandparent characteristics that, in addition to determining their eligibility status, may also have a direct effect on female employment (e.g., age, gender, education, and employment sector and type). ${ }^{11}$

\footnotetext{
${ }^{11}$ Omitting these controls may lead to a spurious correlation between grandparental pension eligibility and female employment. However, the estimates obtained with the saturated models are robust to the presence of time-invariant unobservable grandparent characteristics that drive their educational and employment choices and may also be correlated with female employment. The main assumption is that grandparents who made the same educational and employment choices have similar unobservable characteristics.
} 
We are primarily interested in the role of grandparents as potential providers of child care, and estimate accordingly Equation (1) on a sample of women with young children. Our estimation sample includes every woman aged 20-49 who has at least one child under 15 living in the household. As a validity check, we also estimate it for the sample of women in the same age range who have no children under 15 living in the household and for the sample of their male partners. We focus our attention on the coefficients $\beta_{1}^{k}, \beta_{2}^{k}, \beta_{3}^{k}$, which (multiplied by 100) respectively indicate by how many percentage points a mother is more or less likely to be employed if her relative $k$ has always been out of the labor force, is eligible for state pension and thus potentially retired from the work force, or is not yet eligible for state pension and thus potentially still employed (or job hunting) relative to the case in which $k$ is dead. Given the predominance of women in child care provision, we expect to find a positive effect of the availability of maternal and paternal grandmothers for child care on the women's employment probability but a lower (or no) effect of grandfathers' availability.

Unlike most previous studies, rather than focusing only on the child care availability of maternal grandmothers, we examine that of all grandparents to avoid any omitted variable bias from its correlating with maternal grandmother availability (e.g., because of similar characteristics like age or education) and affecting women's employment. On the other hand, considering the aggregate number of available grandparents could hide heterogeneous effects across grandparents, and for this reason we consider the potential availability for child care of each grandparent individually. Moreover, we include in the estimation sample both women whose parents or in-laws were not alive at the time of interview and those whose parents or in-laws had never participated in the labor market. These two characteristics enable us to not only compute the effect on women's employment of not having living parents and/or in-laws but also test for the presence of heterogeneous effects from parents or in-laws who are available either because they never worked or because they worked in the past and are now retired. These two groups may in fact have very different effects on women's employment. We expect that $\beta_{1}^{k}$ may partly capture cultural effects in addition to the child 
care availability effect. In particular, an intergenerational correlation is possible between a grandmother's employment and her daughter's, reflecting either unobservable variables correlated across generations or a true causal relation (e.g., a gender role model). ${ }^{12}$ Conversely, any negative intergenerational correlation between a woman's employment and her mother's never having participated in the labor market may be partly countervailed by the positive effect produced by the latter's provision of informal child care. The sign of the net effect is therefore an empirical question. Because it is generally hard to find a convincing exogenous source of variation in parental (especially, maternal) lifetime LFP, rather than attaching a strictly causal interpretation to the estimate of $\beta_{2}^{k}-\beta_{1}^{k}$, we consider it only suggestive of potential heterogeneous effects by source of availability. Instead, our main parameter of interest is $\beta_{2}^{k}-\beta_{3}^{k}$, the difference between retirement eligible and ineligible parents or in-laws (whoever worked). These two groups, although very similar in terms of the unobservable variables driving labor force attachment, differ only in their pension rule-induced employment status. We thus interpret this difference causally.

Three other features of our analysis are noteworthy. First, unlike that in IV-based studies, our estimation strategy does not require that the grandparent's retirement eligibility has only an indirect effect on women's employment via grandparental child care. Rather, part of the reduced form (gross) effect estimated of the grandparents' retirement eligibility on the women's employment may be produced by additional causal pathways and not exclusively by grandparental child care. Therefore, to evaluate the relevance of this latter, we implement several placebo tests; in particular, an estimation of Equation (1) that assesses whether the effects are larger for individuals with a greater need for child care than for those who need it less (e.g., women vs. men, women with young children vs. other women). Second, by focusing on parents’ and in-laws’ retirement eligibility and not on their current retirement status (which is an endogenous choice variable), we address a potential reverse causality bias; namely, that some grandparents may anticipate their retirement to

\footnotetext{
${ }^{12}$ See, for instance, Farre and Vella (2013).
} 
take care of their grandchildren with working mothers (Lumsdaine and Vermeer 2014). ${ }^{13}$ Lastly, since not all eligible grandparents actually decide to retire, and not all retired grandparents provide child care to their children's family, our intention-to-treat estimates must be interpreted as lower bound estimates of the effect of grandparent-provided child care on maternal employment.

\section{Data}

Our analysis is based on data from the SHIW, ${ }^{14}$ administered by the Bank of Italy every two years $^{15}$ to a rotating panel of 8,000 households (approximately 24,000 individuals) per year. In addition to focusing on labor market and income-related issues, the survey also gathers information on such relevant topics as education, socio-demographics, consumption, and dwelling characteristics. Besides providing full information on all household members, household heads and their partners also report the birth year, labor market status, educational attainment, and alive or dead status of their parents, ${ }^{16}$ which we use to analyze grandparental availability for child care. Because of data availability and comparability, we focus on the seven waves covering 1993-2006, for a total potential population of 55,163 households.

Because the relevant survey unit in the SHIW is the household, for every unit in the sample we use both household-specific (e.g., residential region, household size and composition) and individual-specific (e.g., demographics, education, labor market outcomes, income) variables for all household members. We also exploit the information on the household heads and their partners' parents. To study the effects of grandparent availability on maternal labor market outcomes, however, we must restrict our sample to a subset of relevant households containing a cohabiting couple who are potential or actual parents. We therefore select all households that include two

\footnotetext{
${ }^{13}$ More generally, Ho (2015) and Rupert and Zanella (2014), among others, show that grandparents' labor supply may be affected by the presence of grandchildren.

14 "Indagine sui bilanci delle famiglie italiane" (Banca d'Italia).

${ }^{15}$ Except for a three-year interval between 1995 and 1998.

${ }^{16}$ For 1998, information on whether grandparents were alive is missing, so for that year, we exploit the panel dimension of SHIW and recover, where possible, the information from other waves.
} 
partners, one a female aged 20-49 for whom we have complete information on both the dependent and independent variables. This selection reduces the sample to 13,443 couples, 8,402 (62.5 percent) of whom are parents to at least one child younger than 15 living in the household, while the remaining couples (5,041, 37.5 percent) either have no offspring or have only children older than 14 or living outside the household.

Table 2 reports the summary statistics for our sample. The women are on average younger than their partners by about four years, slightly more educated, with a considerably lower employment rate, about 51 percent for females versus 94 percent for males. Interestingly, the female employment rate increases with the age of the children: from 55 percent for women with no children or children older than 14 in the household to less than 50 percent for women with children younger than 6 . The grandmothers in the sample are consistently about four years younger than the grandfathers, and the maternal grandparents are four years younger than both paternal grandparents. The grandmothers, however, are less educated than their partners, and their LFP is dramatically lower, less than 30 percent versus about 93 percent for grandfathers. The share of grandparents that are not alive also varies substantially, from a minimum of 15 percent for maternal grandmothers to a maximum of 42 percent for paternal grandfathers. These differences result from the different birth cohorts: grandfathers are older than grandmothers and men older than women, so that paternal grandfathers are the least likely and maternal grandmothers the most likely to be alive.

\section{Pension Eligibility and Retirement}

In this paper, we seek to assess the importance of informal child care provision by grandparents, proxied by their potential availability, on maternal employment. As described in Section III, we divide the grandparents’ potential availability into four categories: not alive, never having worked $(N W)$, or in the labor market and either pension eligible $(E L)$ or pension ineligible $(N E L)$. Because the SHIW asks respondents directly about their grandparents' labor market participation, as well as age, birth year, and employment sector and type information used to 
determine pension eligibility, we have all relevant data except for years of contribution. To derive this variable, we exploit the fact that the SHIW does record years of pension contributions for all individuals interviewed. First, we regress the actual contribution years on a set of individual characteristics (gender, age, education, employment sector and type, year, and region) available for both the grandparent cohort ${ }^{17}$ and the surveyed individual cohort and then predict the grandparents' years of contribution on the basis of the estimated coefficients. ${ }^{18}$ Once these predictions are obtained, we have all necessary information to determine whether every grandparent satisfies at least one of the pension requirements and is thus eligible or ineligible for a pension.

We test pension eligibility as a valid predictor of retirement status by running simple regressions of actual individual retirement status of all surveyed individuals (albeit separately for men and women) on both a constant and imputed pension eligibility indicator. The coefficients estimated on this eligibility indicator are $0.719(\mathrm{SE}=0.006)$ for men and $0.857(\mathrm{SE}=0.005)$ for women, ${ }^{19}$ which, when considered together with our main results (reported below), support the validity of pension eligibility as a predictor of potential child care availability based on actual retirement.

\section{The Effect of Grandparent Availability on Maternal Employment}

\section{A. Main Results}

Table 3 reports the results of estimating Equation (1) for a sample of women aged 20-49 who are either household heads or partners and mothers to at least one child under 15 living in the household. In all cases, the columns reporting the different specifications display the estimated

\footnotetext{
${ }_{17}$ Parents' (in-laws') sectors and types of employment are measured when they had the same age as the respondent (spouse). In case they were unemployed at that time, the characteristics of the last job are reported.

${ }_{18}$ The regression results are reported in Table A1. All regressions using retirement eligibility based on predicted contribution years are bootstrapped (1,000 replications) to account for its being a generated regressor.

${ }^{19}$ Potential eligibility is a better predictor of actual retirement for women than for men, which suggests that (because of special rules for hazardous jobs, as stressed in footnote 10) men anticipate or postpone retirement with respect to pension eligibility, while women are more tied to it. Men could decide to postpone retirement with respect to the minimum eligible age more frequently than women for several reasons, including higher income, a good enough health status to work, social norms, and/or a higher psychological costs of retirement.
} 
coefficients on the three dummy variables $N W, E L$, and $N E L$ for the woman's mother (maternal grandmother), mother-in-law (paternal grandmother), father (maternal grandfather) and father-inlaw (paternal grandfather). Column (1) lists the outcomes for the basic specification, which includes only these 12 variables of interest together with region by year fixed effects and dummies for municipality size $(<20,000,20,000-40,000,40,000-500,000,>500,000$ inhabitants). Column (2) reports the results for an enriched specification that controls for grandparental educational level (up to lower secondary, upper secondary or tertiary, and above), which may proxy for downstream monetary transfers to women, a major channel through which working grandparents may affect women's LFP. It also controls for grandparents' age, which in addition to affecting their pension eligibility may also affect their health status and thus a daughter(-in-law)'s employment. Column (3) adds in a quadratic form for the woman's age and dummies for her educational level, which may significantly affect her employment probability. Column (4) then integrates controls for partner's education and income, both of which may affect female employment. Our key result is consistent throughout all specifications: having a mother who is eligible for a state pension has a positive and strongly statistically significant effect on the employment probability of a 20- to 49-year-old woman who is mother to a resident child under 15.

The magnitude of the effects implied by the estimates in column (4) is sizable: having a pension eligible mother implies that her daughter is 10.5 percentage points more likely to be employed than women whose mother has died, and 8.9 percentage points more likely than those whose mother is currently pension ineligible. ${ }^{20}$ In our sample, the employment probability of women whose mother is dead is 42 percent compared to 59 percent for women whose mother is not yet pension eligible, implying that a mothers' pension eligibility increases her daughter's employment probability by 25 percent relative to having a dead mother and by 15 percent relative to having a mother who is still working. Interestingly, our estimates show no availability effect for

\footnotetext{
${ }^{20}$ The latter effect is measured based on $\beta_{2}-\beta_{3}$, which is reported at the bottom of each column. A test for the hypothesis that $\beta_{2}=\beta_{3}$ rejects the null with a $p$-value of 0.008 .
} 
never employed mothers: in this case, the positive effect of availability for child care is presumably offset by the negative effect of family cultural influences (see Section III). The column (4) results also indicate that a mother-in-law's (paternal grandmother's) pension eligibility implies an increase in employment probability relative not only to women whose mother-in-law has died but also relative to women whose mother-in-law has never worked. Conversely, however, we cannot reject the hypothesis that the effect of a working mother-in-law is the same as that of a pension eligible mother-in-law: the effect for paternal grandmother's, therefore, does not seem to originate from their availability as suppliers of child care. ${ }^{21}$

The models used in columns (1)-(4) of Table 3 identify the effect of grandparental retirement eligibility on maternal employment by simultaneously exploiting within-year and between-year variation across individuals. Because grandparental eligibility is imputed based on observable characteristics, some of which are excluded from the employment equation (i.e., employment sector and type), one possible criticism is that these characteristics may also have a direct effect on maternal employment. Hence, in column (5), we add in dummies for public sector employment and self-employment, allowing us to compare the effect on maternal employment of having grandparents with exactly the same observable characteristics but different pension eligibility. Because grandparental pension eligibility, as defined in Section V, is a nonlinear function of these characteristics, even in this "saturated" model, we still exploit some cross-sectional variation across individuals in grandparental availability. Nevertheless, most identification is achieved through variation in pension eligibility rules over time resulting from the pension reforms described in Section III. This claim is verified by Figure 2, which reports the R-squared of year-specific regressions of each grandparent's pension eligibility status on its determinants. Here, the R-squared remains very high despite increases over time as pension eligibility becomes increasingly linked to

\footnotetext{
${ }^{21}$ Although it would be tempting to interpret these results as further evidence for the role of social norms, together with assortative mating, our most complete specification (column (5)) indicates that once the maternal and paternal grandparents' employment sector and type are controlled for, paternal grandmothers no longer have an effect on the daughter-in-law’s employment probability.
} 
years of contribution, from about 0.75 in 1993 to 0.95 in the 2000s. Thus, after 2000, almost all variation in eligibility status comes from pension reforms.

Quite reassuringly, even in the "saturated" model in column (5), we find that a maternal grandmother's retirement eligibility has a significant 8.7 percentage point greater effect on her daughter's employment probability relative to women whose mothers are dead, which is only marginally smaller than the estimate in column (4). The difference between the coefficients on "mother alive but ineligible" and "mother alive and eligible” amounts to 7.8 percentage points, a 13 percent increase in probability relative to women with ineligible mothers. Moreover, our column (5) estimates show no statistically significant effect of either maternal grandfathers or paternal grandparents on maternal employment probability. In particular, the coefficient on a pension eligible paternal grandmother falls drastically (from 0.065 in column 4 to -0.03 in column (5)) suggesting that the statistically significant association previously estimated may be attributable to characteristics other than retirement eligibility. One potential reading of this result is that paternal grandmother employment characteristics influence the daughter-in-law's partner's attitude toward female employment (Fernández et al., 2004) or even her actual likelihood of finding a job (e.g., through network effects), which both affect her employment status. ${ }^{22}$

\section{B. Insights on the Causal Pathway}

Until now, we have shown that women whose mothers are retirement eligible are significantly more likely to be employed, an effect that does not hold true for the eligibility of their mothers-inlaw. We therefore wonder whether grandparental (potential) availability for child care is a plausible explanation for this finding? If so, we would expect to find evidence that maternal grandparents (grandmothers) are more likely to provide child care than paternal grandparents (grandmothers).

\footnotetext{
${ }^{22}$ Even in the presence of unobserved characteristics that are correlated with grandparental employment sector or type, we still consider the contrast $\beta_{2}^{k}-\beta_{3}^{k}$ to be a valid estimate of the effect of having pension eligible grandparents, because these characteristics are similar across both eligible and ineligible grandparents working in the same employment sector and type. Moreover, later in this section, we also report regression results using definitions of retirement eligibility that are not based on grandparental labor market characteristics.
} 
Extant research supports this view: a greater investment in child care by maternal grandmothers is a very robust pattern in the sociological, psychological, and evolutionary literature (Coall et al. 2014), one recorded for several countries, including the UK, the U.S., Australia, Italy, and Norway (see Whelan 2013, Arpino et al. 2014).

We further check the plausibility of the child care explanation in several interrelated ways. First, we re-estimate Equation (1) for a sample of female household heads or their partners, again in the 20-49 age range, who are not mothers to any cohabiting children under the age of 15 . For these women, the potential availability of maternal or paternal grandparents for child care should have no effect on employment. We report the results for this alternative sample in column (2) of Table 4 with a focus on the most complete specification (equivalent to that in column (5) of Table 3, whose results we repeat for convenience in column (1) of Table 4). These outcomes offer further support for our interpretation of the effects: for women who have no cohabiting children under 15 , there is no indication of a positive effect of the availability of maternal or paternal grandparents on employment probability.

We then perform an even more informative validation test for our proposed explanation by estimating Equation (1) on the subsample of male partners in the estimation sample. Because men are typically less involved in child care activities ${ }^{23}$ (especially in a Southern European country like Italy) and have very high LFP, we expect no positive effect of grandparental availability on their employment probability unless this availability affects employment through a channel other than child care. These results, reported in column (3) of Table 4, indicate that neither maternal nor paternal grandparental pension eligibility has any effect on these men’s employment probability. ${ }^{24}$

Our final test for the plausibility of the child care channel as the main driver of our results relies on the fact that the child care burden may be especially high during the child's earliest years,

\footnotetext{
${ }^{23}$ See, for example, OECD (2001) and Bloemen et al. (2010).

${ }^{24}$ It is worth noting that men whose fathers-in-law have never been employed are significantly less likely to be employed than men whose fathers-in-law are dead. However, only 1.3 percent of individuals in our sample have a father-in law who has always been out of the labor force, and they are likely to share other unobservable distinctive characteristics.
} 
so it is then that family child care support may be most important in determining maternal LFP. If the availability of child care by a grandmother is driving our results, then the younger her daughter's children, the stronger the effect of the grandmother's pension eligibility should become. Hence, in the last columns of Table 4, we restrict our sample to women who have children under the age of 11 (column (4)) and under the age of 6 (column (5)). As expected, the estimated effect of a grandmother's pension eligibility increases from a baseline of 0.087 for women with children up to 14 to 0.115 and 0.243 for women whose children are under 11 and under 6 (compulsory school starting age), respectively. These estimates imply that women whose children are under 11 are 13 percent (7.6 percentage points) more likely to be employed than women whose children are in the same age range but whose mother is not yet pension eligible. The same difference increases to 34 percent (18.7 percentage points) for women whose children are under 6.

\section{Heterogeneous Effects}

We investigate potential heterogeneity in the grandparental eligibility effect based on two factors: women's educational levels and the potential supply of external child care. Because less educated women generally command lower wages in the labor market, their LFP and employment decisions are more sensitive to the availability of low-cost, flexible grandparent-provided child care than those of highly educated women, who may have access to external child care (Hofferth and Wissoker 1992, Powell 2002). To check this prediction, in column (2) of Table 5, we estimate a saturated model (reported for convenience in column (1)) that additionally includes the interactions between maternal grandmother's eligibility and the educational attainment of the women in our sample of mothers with cohabiting children. We define as highly educated those women who have completed upper secondary education or more, and less educated, those who have completed lower secondary education or less. ${ }^{25}$ Less educated women with pension eligible mothers are 10.1

\footnotetext{
${ }^{25}$ Our definitions are motivated by the fact that in Italy (unlike in the U.S.), tertiary educational achievement is very low. Nevertheless, the results remain robust to defining only women with a university degree as highly educated.
} 
percentage points more likely to be employed than their counterparts with ineligible mothers, a difference that is significant at the 5 percent level. In contrast, the effect for highly educated women, albeit positive, is about 6 percentage points smaller and statistically insignificant.

Because external child care could be a substitute for grandparent-provided child care, we expect the effect of grandparental eligibility to be larger when women have access to fewer child care alternatives. Since public and private formal child care is likely to be more abundant in larger municipalities, in column (3) of Table 5, we report the estimates from a model that interacts grandparental eligibility with the size of the municipality of residence. The results are consistent with theoretical expectations. In smaller municipalities (20,000 inhabitants or less), the eligibleineligible grandmother difference amounts to 12.7 percentage points, while in larger municipalities (over 20,000 inhabitants), the difference is much smaller (2.4 percentage points) and statistically insignificant. $^{26}$

\section{Robustness Checks}

To increase the comparability of our results with studies that investigate LFP rather than employment (see Section II), in Table 6, we report the same models estimated in Table 3 but using as our dependent variable a dichotomous indicator equal to 1 if a woman is employed or unemployed and 0 if she is out of the labor force. Both sets of results are very close: in the saturated model (column (5) of Table 6), among the eight grandparent eligibility variables, only the coefficient on maternal grandmother eligibility is statistically significant at the 5 percent level. Women with pension eligible mothers have an 8.9 and 7.3 percentage point higher LFP probability, respectively, than women whose mothers are dead or pension ineligible. The corresponding effects

\footnotetext{
${ }^{26}$ This result, however, is only suggestive and should be interpreted with caution. First, detailed data on child care availability is only available for recent years; for example, ISTAT only provides regional indicators on public child care since 2004. Second, the supply of public child care is likely to be endogenous and mainly demand driven. Hence, using data from 2004, we regress on a regional level the logarithm of the percentage of municipalities that implemented child care services on the logarithm of the percentage of municipalities with over 20,000 inhabitants (controlling for macro area indicators) and obtain an elasticity of $0.49(t=1.98)$. In the absence of better data, we take this result as suggestive of child care services being more abundant in larger municipalities.
} 
on employment are 8.7 percentage points and 7.8 percentage points, respectively (column (5) of Table 3). The fact that the LFP and employment results are practically indistinguishable strongly suggests the pension eligibility status of maternal grandmothers does indeed capture the effect of their child care provision. In fact, we expect no significant effect on unemployed mothers, who can personally take care of their children.

The availability of informal child care may affect not only employment (or LFP) probability but also the intensive margin of labor supply; that is, the number of hours worked, or even women's productivity, reflected in wages and earnings. Grandparents may, for instance, take care of children when they are ill, reducing the number of maternal absences from work in the short run and possibly even improving the latter's probability of promotion in the long run. To gain an approximate idea of the grandparent availability effect on weekly working hours, hourly wages, and annual earnings, we use the saturated model to estimate logarithmic regressions on the sample of working mothers. The estimated effects of maternal grandmother availability are $0.022,0.045$, and 0.075 on hours, wages, and earnings, respectively, none of which are statistically significant at conventional levels. ${ }^{27}$ Thus, overall, there is no compelling evidence that grandmother availability for child care affects the intensive margin of labor supply or productivity. Grandmothers simply seem to help working women overcome their first important obstacle after having children: remaining attached to the labor force.

One possible concern with our definition of eligibility is that it is based on potentially endogenous variables like grandparents' education, employment sector and type, and years of contributions. To address this issue, we redefine eligibility based purely on age and re-estimate the saturated model. The results, reported in column (2) of Table 7, are similar to (albeit less precisely estimated than) our baseline findings (column (1)): a 0.064 difference in employment between women with and without eligible mothers. This difference is not statistically significant at

\footnotetext{
${ }^{27}$ Because of space constraints, we do not report these estimates here, but they are available upon request from the corresponding author.
} 
conventional levels, possibly because of the noisier imputation of eligibility status, which does not consider the requirements for seniority pensions. Finally, in column (3), we also address the potential endogeneity of grandparents’ LFP decision by additionally imputing eligibility status for those who never worked. The estimated effect is only slightly smaller (0.071) than our baseline estimate (0.078) and statistically significant at the 5 percent level. Overall, these results suggest that our estimated effects of pension eligibility are unlikely to suffer from an endogeneity bias.

The last possible concern that we seek to address is related to our initial sample selection. Our analysis is conditional on women's having children aged 0-14 living in the household. This is our population of interest since we focus on the effect of grandparents' availability of child care on maternal employment. Are mothers a random sample of women with respect to unobservable characteristics potentially affecting labor market behavior? If we were able to observe also childless women entering motherhood, would the effect of grandparents' eligibility be larger or smaller than the one we have reported? In order to give an answer to these questions, we estimate a Heckman selection model, with the main equation for employment and a selection equation for the presence of children aged 0-14 in the household. Although the model is formally identified even without an exclusion restriction (Puhani 2000), we propose an economic identification based on the following “instrument:” a proxy for only-child status of a woman's spouse. SHIW provides the number of non-cohabiting siblings still alive for each individual in a couple. This is likely to be a good proxy of only-child status as mortality is still low in the age groups we consider, and siblings' cohabitation after forming their own families and having children is very rare. The idea behind the use of such an instrument is that being raised as an only-child may affect the spouse's fertility preferences, which are likely to shape the couple's actual fertility. We assume that conditional on all the observables included in our models (such as women's, grandparents' and their partners' characteristics, including the latter's level of education and income), the spouse's only-child status is exogenous with respect to a woman's labor market attachment. We consider only the spouse's only-child status, and not also that of the woman, because previous studies showed that maternal grandparents 
are the most likely to provide child care, and women's only-child status may violate the exclusion restriction assumption if siblings create a higher competition for the maternal grandmother's child care.

Table 8 reports the results of the Heckman selection model. Column (1) shows the coefficients of the selection equation, and column (2) those of the main equation. The spouse's only-child status significantly predicts the presence of young children in the household. Only-child men are 4.5 ( $p$ value $=0.018$ ) percentage points less likely to have cohabiting young children. Interestingly, women with eligible mothers have a 2.9 percentage points higher probability of having young cohabiting children than those with ineligible mothers, a finding consistent with the effect reported by Battistin et al. (2015) on fertility, although the estimate is not statistically significant in our case. ${ }^{28}$ The coefficient on the inverse Mill's ratio is negative, suggesting that the error terms in the selection equation and the employment equation are negatively correlated, but conditioning on a large set of controls is not statistically significant at conventional levels.

In column (2), eligible grandmothers are estimated to increase employment by 7.8 percentage points with respect to non-eligible grandmothers. The effect is the same as that estimated in the model not accounting for selection. Although we do not consider this evidence as definitive proof of the absence of a sample selection bias, which would allow to generalize our estimated effects also to childless women (if they were mothers), it is nonetheless indicative that the bias, if any, should not be severe.

\footnotetext{
${ }^{28}$ This may be due to the different dependent variable used in the two studies. The selection relevant for our study is on the presence of young children in the household, while Battistin et al. (2015) focus on overall fertility. All effects computed for the selection equation are average marginal effects.
} 


\section{Discussion}

Our finding that women whose mothers are unavailable for child care suffer a non-negligible employment penalty relative to those who can potentially count on such informal assistance throws light on the unintended consequences of pension reforms on maternal employment prospects. In particular, they are likely to penalize women whose mothers become unavailable because of a higher retirement age or stricter retirement requirements. On the other hand, it may also be useful to assess the aggregate effect of pension reforms on the average employment probability of all women with children aged $0-14$, an effect specific to this demographic group and not to female employment overall. Overall female employment rates may in fact benefit if a higher retirement age translates into longer retention of women in the work force. What is likely to change is the distribution of employment across different generations of women and between women with and without children.

To throw light on this issue, we carry out back-of-the-envelope computations of the average employment probability in our sample under different retirement rule scenarios while keeping the sample characteristics fixed. More specifically, we use two scenarios: a pre-Amato scenario and a Dini scenario, in which either the rules predating the Amato reform or the Dini rules (see Table 1) are assumed to be in place for the whole period. After first redefining maternal grandmother eligibility based on these different rule sets, we recompute the average employment probabilities for the sample. The results of this exercise are graphed in Figure 3. Subfigure (a) shows only a small impact of the retirement rules on average employment probability, with year differences ranging between 0.64 (1993) and 0.8 (1998) percentage points (see appendix Table A2). These differences correspond to about a 1.5 percent decline in employed mothers. Nevertheless, it must be kept in mind that the main drivers of the average employment differences between the two scenarios are the differences in share of pension eligible grandmothers produced by the retirement rules. These latter depend in turn on the demographic characteristics of our estimation sample. For example, high maternal age at first birth is likely to reduce the reform's impact on female employment in that most 
women will then have mothers who are old enough to be retirement eligible no matter what rules we consider in our simulations. Subfigure (b) then reports the aggregate effect on mothers of preschool children (0-5), for whom, consistent with the results in Table 3, column (5), the interscenario differences increase. We now observe differences between 2.3 (1993) and 3 (1998) percentage points, corresponding to a -4 percent and -5.5 percent decrease in maternal employment. Another potential determinant of the pension reforms' low impact in the sample of all mothers (i.e., with children 0-14) may be that a substantial proportion of maternal grandmothers never participated in the labor market and so are unaffected by the retirement rule changes. Thus, in subfigure (c), which reports the same two scenarios but with average employment probability predicted only for women whose mothers have worked, we observe a much larger gap: the Dini reform has a negative effect on the daughters' employment, which peaks in 2000 and amounts to a 4.5 percent reduction relative to the actual baseline employment of 61.4 percent.

\section{Concluding remarks}

In Southern European countries such as Italy, which are characterized by very low provision of public child care, grandparents offer women an important source of informal child care, which helps them reconcile family and working life. In this paper, therefore, we seek to quantify the effect of such grandparental availability on maternal employment. We focus on Italy for two reasons: First, its female employment rates are among the lowest in Europe, making it important to identify which factors are hindering the entry of more women into the workforce. Second, the changes in pension eligibility requirements introduced by Italy's three recent major pension reforms provide exogenous variation in grandparental availability.

Exploiting this exogenous variation, we estimate that mothers of children under 15 whose own mothers are retirement eligible have a 7.8 percentage points higher probability of employment $(+13$ percent) than those whose mothers are ineligible. We interpret this effect to mean that the availability of maternal grandmothers for child care increases the likelihood of their daughters being 
employed, a conclusion supported by several robustness checks. In fact, we find no such effects for either women with no children under 15 or men and, as could be expected, the magnitude of the effects is larger for women with very young children whose child care needs are most intensive. These findings remain robust even to considering female LFP instead of employment and to using alternative ways of imputing eligibility status. We also show that when fully enforced, the pension reforms imply a 1-1.5 percent yearly reduction on the employment rates of women with children aged $0-14$ and a 5.5 percent yearly reduction for those with children aged $0-5$. Taken together, our results indicate that pension reforms that raise the retirement age, if not coupled with adequate investments in public child care, may have unintended negative consequences on the employment probabilities of females of child-bearing age by robbing households of an important source of flexible, low-cost child care. 


\section{References}

Abendroth, A. K., T. van der Lippe, and I. Maas. 2012. "Social Support and the Working Hours of Employed Mothers in Europe: The Relevance of the State, the Workplace, and the Family.” Social Science Research 41(3):581-597.

Aparicio-Fenoll, A., and M. Vidal-Fernandez. 2015. ”Working Women and Fertility: The Role of Grandmothers’ Labor Force Participation.” CESifo Economic Studies 61(1):123-147.

Arpino, B., C. Pronzato, and L. Tavares. 2014. “The Effect of Grandparental Support on Mothers' Labor Market Participation: An Instrumental Variable Approach.” European Journal of Population 30(4):369-390.

Bailey, M. J., 2006. “More Power to the Pill: The Impact of Contraceptive Freedom on Women's Life Cycle Labor Supply,” Quarterly Journal of Economics 121(1):289-320.

Battistin E., A. Brugiavini, E. Rettore, and G. Weber. 2009. “The Retirement Consumption Puzzle: Evidence from a Regression Discontinuity Approach.” American Economic Review 99(5):2209-2226.

Battistin E., M. De Nadai, and M. Padula. 2015. “Roadblocks on the Road to Grandma's House: Fertility Consequences of Delayed Retirement.” Queen Mary, University of London Working Paper No. 748.

Bloemen, H., S. Pasqua, and E. Stancanelli. 2010. “An Empirical Analysis of the Time Allocation of Italian Couples: Are They Responsive?” Review of Economics of the Household 8(3):345369.

Bottazzi R., T. Jappelli, and M. Padula. 2006. "Retirement Expectations, Pension Reforms, and Their Impact on Private Wealth Accumulation.” Journal of Public Economics 90(12):21872212.

Càceres-Delpiano J. 2012. “Can We Still Learn Something from the Relationship between Fertility and Mother's Employment? Evidence from Developing Countries.” Demography 49(1):151174. 
Coall D. A., S. Hilbrand, and R. Hertwig. 2014. "Predictors of Grandparental Investment Decisions in Contemporary Europe: Biological Relatedness and Beyond.” PLoS ONE 9(1):e84082. doi:10.1371/journal.pone.0084082

Compton, J., and R. A. Pollak. 2014. “Family Proximity, Child Care, and Women’s Labor Force Attachment.” Journal of Urban Economics 79(C):72-90.

Cristia, J. 2008. "The Effect of a First Child on Female Labor Supply: Evidence from Women Seeking Fertility Services.” Journal of Human Resources 43(3):487-510.

Cruces, G. and S. Galiani. 2007. "Fertility and Female Labor Supply in Latin America: New Causal Evidence,” Labour Economics 14(3):565-573.

Del Boca, D. 2002. “The Effect of Child Care and Part Time Opportunities on Participation and Fertility Decisions in Italy.” Journal of Population Economics 15(3):549-573.

Del Boca, D., and R. M. Sauer. 2009. “Life Cycle Employment and Fertility Across Institutional Environments.” European Economic Review 53(3):274-292.

Del Boca. D. and D. Vuri. 2007. “The Mismatch between Employment and Child Care in Italy: The Impact of Rationing,” Journal of Population Economics 20(4):805-832.

Farre, L., and F. Vella. 2013. “The Intergenerational Transmission of Gender Role Attitudes and Its Implications for Female Labour Force Participation.” Economica 80(318):219-247.

Fernández, R., A. Fogli, and C. Olivetti. 2004. "Mothers and Sons: Preference Formation and Female Labor Force Dynamics.” Quarterly Journal of Economics119(4):1249-1299.

Hank, K., and I. Buber. 2009. “Grandparents Caring for Their Grandchildren.” Journal of Family Issues 30(1):53-73.

Ho, C. 2015. “Grandchild Care, Intergenerational Transfers, and Grandparents’ Labor Supply,” Review of Economics of the Household 13(2): 359-384.

Hofferth, S. L., and D. A. Wissoker. 1992. "Price, Quality, and Income in Child Care Choice.” Journal of Human Resources 27(1):70-111. 
Leibowitz, A., J. A. Klerman, and L. J. Waite. 1992. "Employment of New Mothers and Child Care Choice: Differences by Children’s Age.” Journal of Human Resources 27(1):112-133.

Lewbel, A. 2007. "Estimation of Average Treatment Effects with Misclassification," Econometrica 75(2):537-551.

Lumsdaine, R. L. and S. J. C. Vermeer. 2014. "Retirement Timing of Women and the Role of Care Responsibilities for Grandchildren,” NBER Working Papers 20756, National Bureau of Economic Research, Inc.

Maurer-Fazio, M., R. Connelly, and L. Chen. 2011. “Child Care, Eldercare, and Labor Force Participation of Married Women in Urban China, 1982-2000.” Journal of Human Resources 46(2):261-294.

OECD. 2001. “Balancing Work and Family Life: Helping Parents into Paid Employment.” Chapter 4 of Employment Outlook. Paris: OECD Publishing.

OECD. 2012. Closing the Gender Gap: Act Now. Paris: OECD Publishing.

Ogawa, N., and J. F. Ermisch. 1996. "Family Structure, Home Time Demands and the Employment Patterns of Japanese Married Women.” Journal of Labor Economics 14(4):677-702.

Posadas, J., and M. Vidal-Fernandez. 2013. “Grandparents’ Child Care and Female Labor Force Participation.” IZA Journal of Labor Policy 3(14):1-20.

Powell, L. M. 2002. “Joint Labor Supply and Child Care Choice Decisions of Married Mothers.” Journal of Human Resources 37(1):106-128.

Pronzato, C., 2009. "Return to Work After Childbirth: Does Parental Leave Matter in Europe?,” Review of Economics of the Household 7(4):341-360.

Puhani, P. A, 2000. “The Heckman Correction for Sample Selection and Its Critique,” Journal of Economic Surveys 14(1):53-68.

Rupert, P., and G. Zanella. 2014. “Grandchildren and Their Grandparents’ Labor Supply.” Working Paper No. 937, Department of Economic Science, University of Bologna. 
Whelan, S. 2013. "Work or Care? The Labour Market Activity of Grandparents in Australia”, University of Sidney, Mimeo. 


\section{Tables and Figures}

Figure 1. Public expenditure on child care and early education services, percent of GDP, 2011

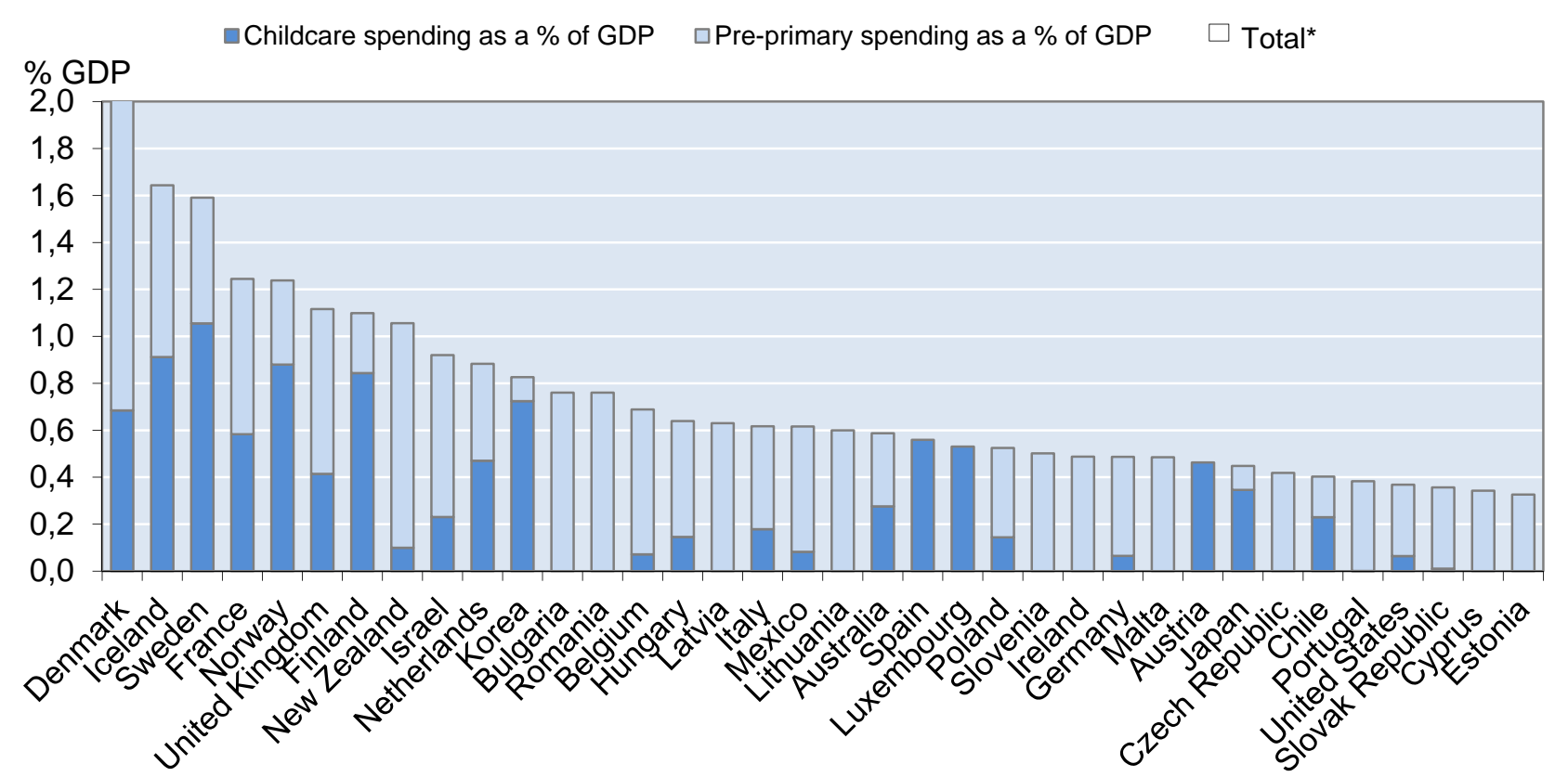

Source: OECD Family Database (http://www.oecd.org/social/family/database.htm), chart PF3.1.

Figure 2. R-squared of year-specific regressions of each grandparent's eligibility status on its determinants

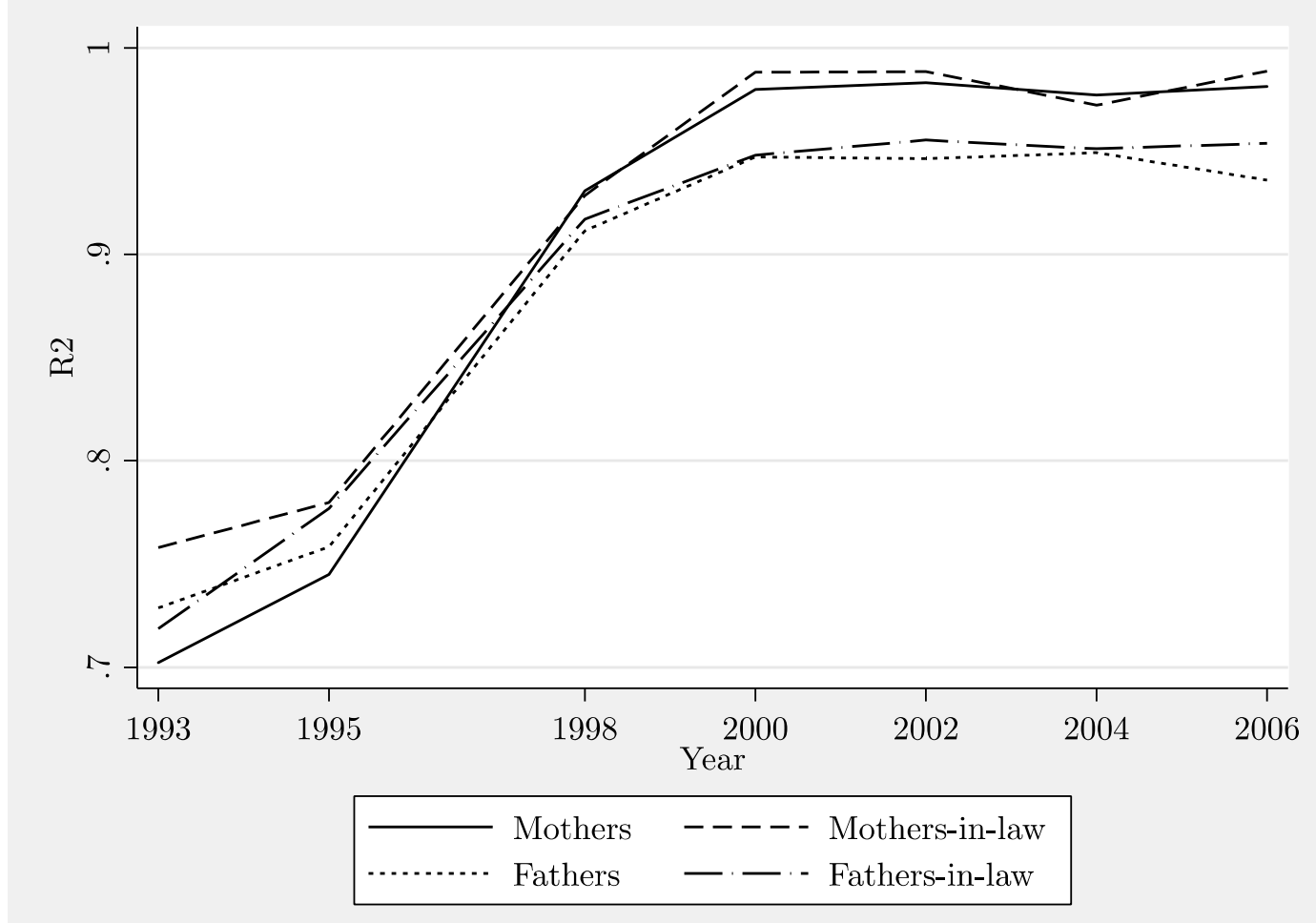

Note. The figure reports the R-squared of year-specific regressions of dichotomous indicators for each grandparent's pension eligibility status (eligible or not) on their age, and dummies for educational attainment, public sector employment, self-employment and region of residence. 
Figure 3. Simulated employment rates in the sample of women with children aged 0-14 (a) and 0-5 (b), and whose mother participated in the labor force (c)

(a)

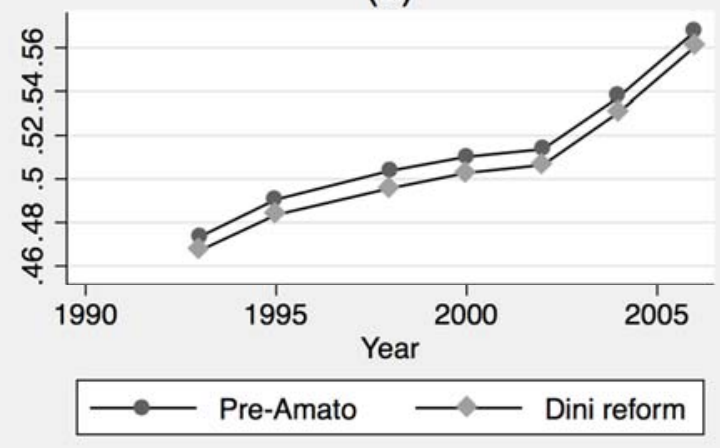

(c)

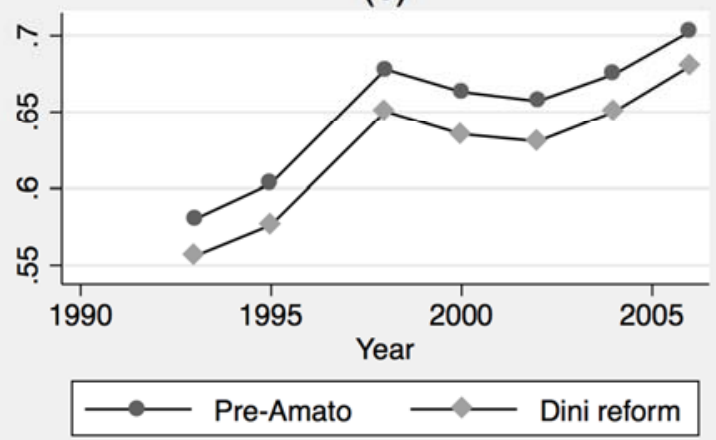

(b)

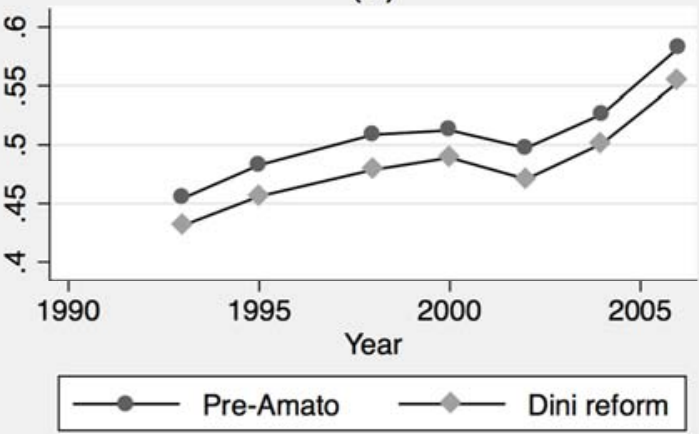

Note. The figure reports the employment rates of different samples of women computed under different set of rules on pension eligibility for their mothers. Specifically, the darker line with circles is drawn under the assumption that in all years the eligibility rules are those that were in place until 1992 (i.e. before the Amato reform), whereas the lighter line with squares is drawn under the assumption that in all years the more restrictive rules set by the 1995 Dini reform apply to everyone. The samples consist of all women with children aged 0-14 in subfigure (a), all women with children aged 0-5 in subfigure (b), and all women with children aged 0-14, whose mothers participated in the labor force in subfigure (c). 
Table 1

Eligibility Criteria of Italy's Pension Reforms

\begin{tabular}{|c|c|c|c|c|c|c|c|c|c|c|c|c|c|c|c|c|c|c|c|c|}
\hline \multirow{5}{*}{\begin{tabular}{c||} 
Law \\
Criterion \\
\\
Sector \\
Gender \\
Requirement \\
\end{tabular}} & \multicolumn{10}{|c|}{ Amato reform } & \multicolumn{8}{|c|}{ Dini - Prodi reform } & \multirow{2}{*}{\multicolumn{2}{|c|}{\begin{tabular}{|c|} 
Dini reform \\
Seniority
\end{tabular}}} \\
\hline & \multicolumn{4}{|c|}{ Private } & \multicolumn{4}{|c|}{$\begin{array}{c}\text { Public and } \\
\text { self-employed }\end{array}$} & \multirow{4}{*}{$\begin{array}{c}\text { Seniori } \\
\text { Private and } \\
\text { self- } \\
\text { employed } \\
\text { All } \\
\text { Only } \\
\text { Contr. } \\
\end{array}$} & \multirow{4}{*}{\begin{tabular}{|} 
Public \\
\begin{tabular}{|c|} 
All \\
Only \\
Contr.
\end{tabular} \\
\end{tabular}} & \multirow{3}{*}{\multicolumn{2}{|c|}{$\begin{array}{c}\text { Private } \\
\text { All } \\
\text { Jointly }\end{array}$}} & \multirow{3}{*}{\multicolumn{2}{|c|}{$\begin{array}{c}\text { Public } \\
\text { All } \\
\text { Jointly }\end{array}$}} & \multirow{3}{*}{\multicolumn{2}{|c|}{$\begin{array}{c}\text { Self- } \\
\text { employed } \\
\text { All } \\
\text { Jointly }\end{array}$}} & \multirow{4}{*}{$\begin{array}{c}\text { Private } \\
\text { and } \\
\text { public } \\
\text { All } \\
\text { Only } \\
\text { Contr. }\end{array}$} & \multirow{4}{*}{$\begin{array}{c}\text { Self- } \\
\text { employed } \\
\text { All } \\
\text { Only } \\
\text { Contr. } \\
\end{array}$} & & \\
\hline & \multirow{2}{*}{\multicolumn{2}{|c|}{$\begin{array}{l}\text { Males } \\
\text { Jointly }\end{array}$}} & \multirow{2}{*}{\multicolumn{2}{|c|}{$\begin{array}{c}\text { Females } \\
\text { Jointly }\end{array}$}} & \multirow{2}{*}{\multicolumn{2}{|c|}{$\begin{array}{l}\text { Males } \\
\text { Jointly }\end{array}$}} & \multirow{2}{*}{\multicolumn{2}{|c|}{$\begin{array}{c}\text { Females } \\
\text { Jointly }\end{array}$}} & & & & & & & & & & & All & All \\
\hline & & & & & & & & & & & & & & & & & & & Only & Only \\
\hline & Age & Contr. & Age & Contr. & Age & Contr. & Age & Contr. & & & Age & Contr. & Age & Contr. & Age & Contr. & & & Age & Contr. \\
\hline 1993 & 60 & 15 & 55 & 15 & 65 & 15 & 60 & 15 & 35 & 20 & & & & & & & & & & \\
\hline 1994 & 61 & 16 & 56 & 16 & 65 & 16 & 60 & 16 & 35 & 20 & & & & & & & & & & \\
\hline 01-06/1995 & 61 & 17 & 56 & 17 & 65 & 17 & 60 & 17 & 35 & 20 & & & & & & & & & & \\
\hline 07-12/1995 & 62 & 17 & 57 & 17 & 65 & 17 & 60 & 17 & 35 & 20 & & & & & & & & & & \\
\hline 1996 & 62 & 17 & 57 & 17 & 65 & 17 & 60 & 17 & & & 52 & 36 & 52 & 36 & 52 & 36 & & & 65 & 40 \\
\hline 1997 & 63 & 18 & 58 & 18 & 65 & 18 & 60 & 18 & & & 52 & 36 & 52 & 36 & 52 & 36 & & & 65 & 40 \\
\hline 01-06/1998 & 63 & 18 & 58 & 18 & 65 & 18 & 60 & 18 & & & 54 & 35 & 53 & 35 & 57 & 35 & 36 & 40 & 65 & 40 \\
\hline 07-12/1998 & 64 & 18 & 59 & 18 & 65 & 18 & 60 & 18 & & & 54 & 35 & 53 & 35 & 57 & 35 & 36 & 40 & 65 & 40 \\
\hline 1999 & 64 & 19 & 59 & 19 & 65 & 19 & 60 & 19 & & & 55 & 35 & 53 & 35 & 57 & 35 & 37 & 40 & 65 & 40 \\
\hline 2000 & 65 & 19 & 60 & 19 & 65 & 19 & 60 & 19 & & & 55 & 35 & 54 & 35 & 57 & 35 & 37 & 40 & 65 & 40 \\
\hline 2001 & 65 & 20 & 60 & 20 & 65 & 20 & 60 & 20 & & & 56 & 35 & 55 & 35 & 58 & 35 & 37 & 40 & 65 & 40 \\
\hline 2002 & 65 & 20 & 60 & 20 & 65 & 20 & 60 & 20 & & & 57 & 35 & 55 & 35 & 58 & 35 & 37 & 40 & 65 & 40 \\
\hline 2003 & 65 & 20 & 60 & 20 & 65 & 20 & 60 & 20 & & & 57 & 35 & 56 & 35 & 58 & 35 & 37 & 40 & 65 & 40 \\
\hline 2004 & 65 & 20 & 60 & 20 & 65 & 20 & 60 & 20 & & & 57 & 35 & 57 & 35 & 58 & 35 & 38 & 40 & 65 & 40 \\
\hline 2005 & 65 & 20 & 60 & 20 & 65 & 20 & 60 & 20 & & & 57 & 35 & 57 & 35 & 58 & 35 & 38 & 40 & 65 & 40 \\
\hline 2006 & 65 & 20 & 60 & 20 & 65 & 20 & 60 & 20 & & & 57 & 35 & 57 & 35 & 58 & 35 & 39 & 40 & 65 & 40 \\
\hline 2007 & 65 & 20 & 60 & 20 & 65 & 20 & 60 & 20 & & & 57 & 35 & 57 & 35 & 58 & 35 & 39 & 40 & 65 & 40 \\
\hline
\end{tabular}

Note. This table reports the retirement age and contribution (Contr.) requirements of the different pension laws. 
Table 2

Sample Summary Statistics

Panel A: Women and their partners

\begin{tabular}{|c|c|c|c|c|}
\hline & \multicolumn{2}{|c|}{ Women } & \multicolumn{2}{|c|}{ Men } \\
\hline & Freq. & $\%$ & Freq. & $\%$ \\
\hline Employed (children 0-14) & 4253 & 50.62 & 7912 & 94.17 \\
\hline Employed (children 0-10)* & $3272 / 6479$ & 50.50 & & \\
\hline Employed (children 0-5)* & $1878 / 3803$ & 49.38 & & \\
\hline Employed (no children 0-14)* & $2772 / 5041$ & 54.99 & & \\
\hline Lower secondary or less & 4028 & 47.94 & 4285 & 51.00 \\
\hline Upper secondary & 3463 & 41.22 & 3199 & 38.07 \\
\hline Tertiary or above & 911 & 10.84 & 918 & 10.93 \\
\hline & Obs. & $\begin{array}{c}\text { Mean } \\
(S D)\end{array}$ & Obs. & $\begin{array}{l}\text { Mean } \\
(S D)\end{array}$ \\
\hline Age & 8402 & $\begin{array}{c}37.0 \\
(5.97)\end{array}$ & 8402 & $\begin{array}{l}40.55 \\
(6.60)\end{array}$ \\
\hline Income & 8402 & $\begin{array}{c}6932 \\
(9111)\end{array}$ & 8402 & $\begin{array}{c}21204 \\
(21457)\end{array}$ \\
\hline
\end{tabular}

Panel B: Grandparents

\begin{tabular}{lcccccccc}
\hline \hline & \multicolumn{2}{c}{ Mothers } & \multicolumn{2}{c}{ Mothers-in-law } & \multicolumn{2}{c}{ Fathers } & \multicolumn{2}{c}{ Fathers-in-law } \\
\hline \hline & Freq. & $\%$ & Freq. & $\%$ & Freq. & $\%$ & Freq. & $\%$ \\
\hline Not alive & 1247 & 14.84 & 1797 & 21.39 & 2806 & 33.40 & 3532 & 42.04 \\
Alive and never worked & 4775 & 56.83 & 4626 & 55.06 & 126 & 1.50 & 106 & 1.26 \\
Alive and eligible & 1715 & 20.41 & 1603 & 19.08 & 3686 & 43,87 & 3699 & 44.03 \\
Alive and ineligible & 665 & 7.91 & 376 & 4.48 & 1784 & 21.21 & 1065 & 12.68 \\
\hline Lower secondary or less & 7685 & 91.47 & 7795 & 92.78 & 7335 & 87.30 & 7482 & 89.05 \\
Upper secondary & 576 & 6.86 & 491 & 5.84 & 752 & 8.95 & 620 & 7.38 \\
Tertiary or above & 141 & 1.68 & 116 & 1.38 & 315 & 3.75 & 300 & 3.57 \\
\hline Private sector & 1980 & 23.57 & 1868 & 22.23 & 6526 & 77.67 & 6580 & 78.31 \\
Public sector & 534 & 6.36 & 417 & 4.96 & 1280 & 15.23 & 1310 & 15.59 \\
Never worked & 5888 & 70.08 & 6117 & 72.80 & 596 & 7.09 & 512 & 6.09 \\
\hline Self-employed & 822 & 9.78 & 807 & 9.60 & 2129 & 25.34 & 2323 & 27.65 \\
\hline \hline & Obs. & Mean & Obs. & Mean & Obs. & Mean & Obs. & Mean \\
& $(S D)$ & & $(S D)$ & & $(S D)$ & $(S D)$ \\
\hline Age & 8402 & 65.7 & 8402 & 69.0 & 8402 & 69.6 & 8402 & 73.1 \\
& & $(9.12)$ & & $(9.47)$ & & $(9.56)$ & $(10.07)$ \\
\hline \hline
\end{tabular}

Note. Except for the variables marked with an asterisk, whose sample size is reported next to the frequency, statistics are reported for the baseline sample of 8,402 women aged 20-49 who have at least one child under 15 living in the household. 
Table 3

Effect of Grandparent Availability on the Employment of Women with Children under 15

\begin{tabular}{|c|c|c|c|c|c|}
\hline Dep.var.: Woman employed & (1) & (2) & (3) & (4) & (5) \\
\hline \multicolumn{6}{|l|}{ Mothers } \\
\hline \multirow[t]{2}{*}{ Alive and never worked } & 0.038 & 0.040 & 0.021 & 0.019 & 0.026 \\
\hline & $(0.026)$ & $(0.026)$ & $(0.026)$ & $(0.025)$ & $(0.026)$ \\
\hline \multirow[t]{2}{*}{ Alive and eligible } & $0.151^{* * *}$ & $0.131^{* * *}$ & $0.108^{* * *}$ & $0.105^{* * *}$ & $0.087 * *$ \\
\hline & $(0.029)$ & $(0.029)$ & $(0.029)$ & $(0.029)$ & $(0.042)$ \\
\hline \multirow{2}{*}{ Alive and ineligible } & 0.054 & 0.047 & 0.022 & 0.016 & 0.009 \\
\hline & $(0.040)$ & $(0.041)$ & $(0.040)$ & $(0.039)$ & $(0.048)$ \\
\hline \multicolumn{6}{|l|}{ Mothers-in-law } \\
\hline \multirow[t]{2}{*}{ Alive and never worked } & 0.036 & 0.037 & 0.025 & 0.023 & 0.042 \\
\hline & $(0.024)$ & $(0.024)$ & $(0.026)$ & $(0.026)$ & $(0.028)$ \\
\hline \multirow[t]{2}{*}{ Alive and eligible } & $0.096 * * *$ & $0.086 * * *$ & $0.065 * *$ & $0.065 * *$ & -0.003 \\
\hline & $(0.027)$ & $(0.028)$ & $(0.029)$ & $(0.029)$ & $(0.039)$ \\
\hline \multirow[t]{2}{*}{ Alive and ineligible } & $0.082 *$ & $0.084^{*}$ & 0.074 & 0.070 & 0.019 \\
\hline & $(0.047)$ & $(0.048)$ & $(0.047)$ & $(0.047)$ & $(0.052)$ \\
\hline \multicolumn{6}{|l|}{ Fathers } \\
\hline \multirow[t]{2}{*}{ Alive and never worked } & 0.035 & 0.044 & 0.052 & 0.051 & 0.072 \\
\hline & $(0.060)$ & $(0.060)$ & $(0.060)$ & $(0.060)$ & $(0.068)$ \\
\hline \multirow[t]{2}{*}{ Alive and eligible } & 0.016 & 0.018 & -0.001 & -0.002 & -0.004 \\
\hline & $(0.021)$ & $(0.021)$ & $(0.020)$ & $(0.020)$ & $(0.020)$ \\
\hline \multirow[t]{2}{*}{ Alive and ineligible } & -0.037 & 0.000 & -0.008 & -0.007 & -0.003 \\
\hline & $(0.026)$ & $(0.031)$ & $(0.029)$ & $(0.029)$ & $(0.029)$ \\
\hline \multicolumn{6}{|l|}{ Fathers in law } \\
\hline \multirow[t]{2}{*}{ Alive and never worked } & $-0.133 *$ & -0.104 & -0.097 & -0.100 & -0.073 \\
\hline & $(0.072)$ & $(0.070)$ & $(0.070)$ & $(0.070)$ & $(0.078)$ \\
\hline \multirow[t]{2}{*}{ Alive and eligible } & 0.023 & 0.027 & 0.001 & -0.002 & -0.003 \\
\hline & $(0.020)$ & $(0.020)$ & $(0.019)$ & $(0.019)$ & $(0.020)$ \\
\hline \multirow[t]{2}{*}{ Alive and ineligible } & -0.025 & 0.001 & -0.016 & -0.020 & -0.010 \\
\hline & $(0.028)$ & $(0.032)$ & $(0.030)$ & $(0.030)$ & $(0.031)$ \\
\hline Grandparent's age (linear and squared) and education & No & Yes & Yes & Yes & Yes \\
\hline Woman's age (linear and squared) and education & No & No & Yes & Yes & Yes \\
\hline Partner's education and income & No & No & No & Yes & Yes \\
\hline Grandparent's employment sector and type & No & No & No & No & Yes \\
\hline Municipality size & Yes & Yes & Yes & Yes & Yes \\
\hline Region $\times$ year fixed effects & Yes & Yes & Yes & Yes & Yes \\
\hline Observations & 8402 & 8402 & 8402 & 8402 & 8402 \\
\hline "Mother alive eligible - Mother alive ineligible & $0.097 * * *$ & $0.083 * *$ & $0.086 * *$ & $0.089 * * *$ & $0.078 * *$ \\
\hline Employed women if mother alive ineligible & $59.25 \%$ & $59.25 \%$ & $59.25 \%$ & $59.25 \%$ & $59.25 \%$ \\
\hline
\end{tabular}


Table 4

Effect of Grandparental Availability on Employment by Gender and Child Age

\begin{tabular}{|c|c|c|c|c|c|}
\hline & Baseline & No child $<15$ & Man & $0-10$ & $0-5$ \\
\hline Dep.var.: Woman employed & $(1)$ & $(2)$ & (3) & $(4)$ & $(5)$ \\
\hline \multicolumn{6}{|l|}{ Mothers } \\
\hline \multirow[t]{2}{*}{ Alive and never worked } & 0.026 & -0.008 & -0.010 & 0.046 & 0.049 \\
\hline & $(0.026)$ & $(0.032)$ & $(0.012)$ & $(0.029)$ & $(0.038)$ \\
\hline \multirow[t]{2}{*}{ Alive and eligible } & $0.087 * *$ & 0.003 & -0.012 & $0.115^{* *}$ & $0.243 * * *$ \\
\hline & $(0.042)$ & $(0.044)$ & $(0.019)$ & $(0.051)$ & $(0.066)$ \\
\hline \multirow[t]{2}{*}{ Alive and ineligible } & 0.009 & 0.065 & -0.034 & 0.039 & 0.056 \\
\hline & $(0.048)$ & $(0.050)$ & $(0.021)$ & $(0.056)$ & $(0.071)$ \\
\hline \multicolumn{6}{|l|}{ Mothers-in-law } \\
\hline \multirow[t]{2}{*}{ Alive and never worked } & 0.042 & 0.001 & 0.017 & $0.059 *$ & $0.077^{*}$ \\
\hline & $(0.028)$ & $(0.028)$ & $(0.012)$ & $(0.033)$ & $(0.042)$ \\
\hline \multirow[t]{2}{*}{ Alive and eligible } & -0.003 & 0.026 & 0.022 & -0.038 & -0.069 \\
\hline & $(0.039)$ & $(0.039)$ & $(0.019)$ & $(0.044)$ & $(0.056)$ \\
\hline \multirow[t]{2}{*}{ Alive and ineligible } & 0.019 & 0.033 & 0.027 & 0.005 & -0.028 \\
\hline & $(0.052)$ & $(0.058)$ & $(0.023)$ & $(0.057)$ & $(0.061)$ \\
\hline Fathers & & & & & \\
\hline \multirow[t]{2}{*}{ Alive and never worked } & 0.072 & -0.026 & 0.045 & 0.065 & 0.124 \\
\hline & $(0.068)$ & $(0.079)$ & $(0.038)$ & $(0.076)$ & $(0.088)$ \\
\hline \multirow[t]{2}{*}{ Alive and eligible } & -0.004 & -0.001 & 0.007 & -0.018 & 0.003 \\
\hline & $(0.020)$ & $(0.024)$ & $(0.009)$ & $(0.022)$ & $(0.031)$ \\
\hline \multirow[t]{2}{*}{ Alive and ineligible } & -0.003 & -0.027 & 0.007 & -0.018 & 0.009 \\
\hline & $(0.029)$ & $(0.039)$ & $(0.015)$ & $(0.031)$ & $(0.040)$ \\
\hline \multicolumn{6}{|l|}{ Fathers in law } \\
\hline \multirow[t]{2}{*}{ Alive and never worked } & -0.073 & $-0.200 *$ & $-0.102 * *$ & -0.084 & -0.179 \\
\hline & $(0.078)$ & $(0.104)$ & $(0.051)$ & $(0.084)$ & $(0.112)$ \\
\hline \multirow[t]{2}{*}{ Alive and eligible } & -0.003 & 0.021 & -0.004 & 0.004 & 0.016 \\
\hline & $(0.020)$ & $(0.024)$ & $(0.009)$ & $(0.021)$ & $(0.027)$ \\
\hline \multirow[t]{2}{*}{ Alive and ineligible } & -0.010 & -0.021 & -0.012 & -0.028 & -0.028 \\
\hline & $(0.031)$ & $(0.048)$ & $(0.014)$ & $(0.033)$ & $(0.039)$ \\
\hline Grandparent's age (linear and squared) and education & Yes & Yes & Yes & Yes & Yes \\
\hline Woman's age (linear and squared) and education & Yes & Yes & Yes & Yes & Yes \\
\hline Partner's education and income & Yes & Yes & Yes & Yes & Yes \\
\hline Grandparent's employment sector and type & Yes & Yes & Yes & Yes & Yes \\
\hline Municipality size & Yes & Yes & Yes & Yes & Yes \\
\hline Region $\times$ year fixed effects & Yes & Yes & Yes & Yes & Yes \\
\hline Observations & 8402 & 5041 & 8402 & 6479 & 3803 \\
\hline Mother alive eligible - Mother alive ineligible & $0.078 * *$ & -0.062 & 0.022 & $0.076 * *$ & $0.187 * * *$ \\
\hline Employed women if mother alive ineligible & $59.25 \%$ & $74.83 \%$ & $59.25 \%$ & $58.31 \%$ & $54.96 \%$ \\
\hline
\end{tabular}

Note: The sample includes women household aged 20-49, who have at least one child under 15 living in the household. Standard errors in parenthesis are bootstrapped and clustered by household, observations are weighted, and the omitted category for availability status is being dead. Column (1) is the baseline model from Table 4, column (5); column (2) shows the baseline model replicated for the sample of women who have no children aged 0-14 living in the household; column (3) refers to the male partners of the women in column (1) (consistent with other models, Mothers and Fathers are maternal grandparents, while in-law's are paternal grandparents); columns (4) to (6) include only the subsamples of women who have children aged $0-10,0-5$, and $0-3$, respectively. ${ }^{*} p$-value $<0.1,{ }^{* *} p$-value $<.05,{ }^{* * *} p$-value $<.01$. 


\section{Table 5}

Effect of Grandparental Availability on the Employment of Women with Children under 15 by Educational Level and Municipal Size

\begin{tabular}{lcccc}
\hline \hline & & Baseline & Education & Municipality size \\
\hline \hline Dep.var.: Woman employed & & $(1)$ & $(2)$ & $(4)$ \\
\hline & Mothers & & & \\
Alive and never worked & & 0.026 & 0.024 & 0.027 \\
& & $(0.026)$ & $(0.025)$ & $(0.025)$ \\
Alive and eligible & $0.087^{* *}$ & & \\
Alive and ineligible & $(0.042)$ & & \\
& & 0.009 & &
\end{tabular}

By educational level

Alive and eligible: Low educated mothers $\quad 0.104^{* *}$

$(0.05)$

$\begin{array}{ll}\text { Alive and eligible: High educated mothers } & 0.067\end{array}$

Alive and ineligible: Low educated mothers

0.003

$(0.056)$

0.008

Alive and ineligible: High educated mothers

(0.059)

By size of municipality of residence

Alive and eligible: Small municipalities

Alive and eligible: Large municipalities

Alive and ineligible: Small municipalities

Alive and ineligible: Large municipalities

\begin{tabular}{|c|c|c|c|}
\hline Mothers-in-law & Yes & Yes & Yes \\
\hline Fathers & Yes & Yes & Yes \\
\hline Fathers-in-law & Yes & Yes & Yes \\
\hline Grandparent's age (linear and squared) and education & Yes & Yes & Yes \\
\hline Woman's age (linear and squared) and education & Yes & Yes & Yes \\
\hline Partner's education and income & Yes & Yes & Yes \\
\hline Grandparent's employment sector and type & Yes & Yes & Yes \\
\hline Municipality size & Yes & Yes & Yes \\
\hline Region $\times$ year fixed effects & Yes & Yes & Yes \\
\hline Observations & 8402 & 8402 & 8402 \\
\hline "Mother alive eligible - Mother alive ineligible & $0.078 * *$ & & \\
\hline Mother alive eligible - Mother alive ineligible (low education) & & $0.101^{* *}$ & \\
\hline Mother alive eligible - Mother alive ineligible (high education) & & 0.059 & \\
\hline Mother alive eligible - Mother alive ineligible (small municipality) & & & $0.127 * *$ \\
\hline Mother alive eligible - Mother alive ineligible (large municipality) & & & 0.024 \\
\hline Employed women if mother alive ineligible & $59.25 \%$ & $59.25 \%$ & $59.25 \%$ \\
\hline
\end{tabular}

Note: The sample includes women aged 20-49, who have at least one child under 15 living in the household. Standard errors in parenthesis are bootstrapped and clustered by household, observations are weighted, and the omitted category for availability status is being dead. Column (1) is the baseline model from Table 4, column (5); column (2) shows the grandparental availability of those who have ever worked interacted with the woman's education ( "high" = upper secondary or more; "low" = lower secondary or less); column (3) shows the grandparental availability of those who have ever worked interacted with the size of the woman's municipality of residence ("small" = 20,000 residents or less; "large" = over 20,000). Even though we computed all the coefficients for the woman's father and in-laws, these are not reported in the table. ${ }^{*} p$-value $<0.1$, ${ }^{* *} p$-value $<.05$, $* * * p$-value $<.01$. 
Table 6

Effect of Grandparental Availability on the LFP of Women with Children under 15

\begin{tabular}{|c|c|c|c|c|c|}
\hline Dep.var.: Woman in the labor force & $(1)$ & $(2)$ & (3) & $(4)$ & $(5)$ \\
\hline \multicolumn{6}{|l|}{ Mothers } \\
\hline \multirow[t]{2}{*}{ Alive and never worked } & $0.045^{*}$ & $0.047^{*}$ & 0.028 & 0.027 & 0.033 \\
\hline & $(0.026)$ & $(0.026)$ & $(0.026)$ & $(0.026)$ & $(0.026)$ \\
\hline \multirow[t]{2}{*}{ Alive and eligible } & $0.153 * * *$ & $0.135 * * *$ & $0.113 * * *$ & $0.110 * * *$ & $0.089 * *$ \\
\hline & $(0.029)$ & $(0.029)$ & $(0.030)$ & $(0.029)$ & $(0.043)$ \\
\hline \multirow[t]{2}{*}{ Alive and ineligible } & 0.066 & 0.057 & 0.032 & 0.026 & 0.016 \\
\hline & $(0.041)$ & $(0.042)$ & $(0.041)$ & $(0.041)$ & $(0.050)$ \\
\hline \multicolumn{6}{|l|}{ Mothers-in-law } \\
\hline \multirow[t]{2}{*}{ Alive and never worked } & 0.032 & 0.031 & 0.019 & 0.018 & 0.042 \\
\hline & $(0.024)$ & $(0.025)$ & $(0.026)$ & $(0.026)$ & $(0.029)$ \\
\hline \multirow[t]{2}{*}{ Alive and eligible } & $0.103 * * *$ & $0.093 * * *$ & $0.073 * *$ & $0.074 * * *$ & -0.016 \\
\hline & $(0.027)$ & $(0.028)$ & $(0.029)$ & $(0.029)$ & $(0.037)$ \\
\hline \multirow[t]{2}{*}{ Alive and ineligible } & $0.098 * *$ & $0.087^{*}$ & 0.078 & 0.075 & 0.004 \\
\hline & $(0.050)$ & $(0.051)$ & $(0.050)$ & $(0.050)$ & $(0.054)$ \\
\hline \multicolumn{6}{|l|}{ Fathers } \\
\hline \multirow[t]{2}{*}{ Alive and never worked } & 0.052 & 0.056 & 0.063 & 0.063 & 0.080 \\
\hline & $(0.060)$ & $(0.060)$ & $(0.060)$ & $(0.060)$ & $(0.067)$ \\
\hline \multirow[t]{2}{*}{ Alive and eligible } & 0.016 & 0.016 & -0.003 & -0.002 & -0.004 \\
\hline & $(0.021)$ & $(0.021)$ & $(0.020)$ & $(0.020)$ & $(0.020)$ \\
\hline \multirow[t]{2}{*}{ Alive and ineligible } & $-0.045^{*}$ & -0.017 & -0.024 & -0.024 & -0.020 \\
\hline & $(0.025)$ & $(0.029)$ & $(0.028)$ & $(0.028)$ & $(0.028)$ \\
\hline \multicolumn{6}{|l|}{ Fathers in law } \\
\hline \multirow[t]{2}{*}{ Alive and never worked } & $-0.156^{* *}$ & $-0.140 * *$ & $-0.133^{*}$ & $-0.135 * *$ & -0.113 \\
\hline & $(0.070)$ & $(0.068)$ & $(0.069)$ & $(0.068)$ & $(0.077)$ \\
\hline \multirow[t]{2}{*}{ Alive and eligible } & 0.019 & 0.020 & -0.005 & -0.008 & -0.011 \\
\hline & $(0.020)$ & $(0.021)$ & $(0.020)$ & $(0.020)$ & $(0.020)$ \\
\hline \multirow[t]{2}{*}{ Alive and ineligible } & -0.023 & -0.010 & -0.027 & -0.030 & -0.020 \\
\hline & $(0.027)$ & $(0.032)$ & $(0.030)$ & $(0.030)$ & $(0.031)$ \\
\hline Grandparent's age (linear and squared) and education & No & Yes & Yes & Yes & Yes \\
\hline Woman's age (linear and squared) and education & No & No & Yes & Yes & Yes \\
\hline Partner’s education and income & No & No & No & Yes & Yes \\
\hline Grandparent's employment sector and type & No & No & No & No & Yes \\
\hline Municipality size & Yes & Yes & Yes & Yes & Yes \\
\hline Region $\times$ year fixed effects & Yes & Yes & Yes & Yes & Yes \\
\hline Observations & 8402 & 8402 & 8402 & 8402 & 8402 \\
\hline Mother alive eligible - Mother alive ineligible & $0.087 * *$ & $0.078 * *$ & $0.081 * *$ & $0.083^{* *}$ & $0.073 * *$ \\
\hline Employed women if mother alive ineligible & $62.26 \%$ & $62.26 \%$ & $62.26 \%$ & $62.26 \%$ & $62.26 \%$ \\
\hline
\end{tabular}




\section{Table 7}

Effect of grandparental availability on the Employment of Women with Children under 15 under Different Imputations of Retirement Eligibility

\begin{tabular}{|c|c|c|c|}
\hline & \multicolumn{3}{|c|}{ Basis for eligibility } \\
\hline & $\begin{array}{c}\text { Our } \\
\text { definition } \\
\end{array}$ & Age only & Age only \\
\hline Dep.var.: Woman employed & $(1)$ & $(2)$ & (3) \\
\hline \multicolumn{4}{|l|}{ Mothers } \\
\hline Alive and never worked & $\begin{array}{c}0.026 \\
(0.026)\end{array}$ & $\begin{array}{c}0.028 \\
(0.026)\end{array}$ & \\
\hline Alive and eligible & $\begin{array}{c}0.087 * * \\
(0.042)\end{array}$ & $\begin{array}{c}0.068 \\
(0.042)\end{array}$ & $\begin{array}{c}0.043^{*} \\
(0.025)\end{array}$ \\
\hline Alive and ineligible & $\begin{array}{c}0.009 \\
(0.048)\end{array}$ & $\begin{array}{c}0.004 \\
(0.054)\end{array}$ & $\begin{array}{c}-0.028 \\
(0.041)\end{array}$ \\
\hline \multicolumn{4}{|l|}{ Mothers-in-law } \\
\hline Alive and never worked & $\begin{array}{c}0.042 \\
(0.028)\end{array}$ & $\begin{array}{c}0.042 \\
(0.028)\end{array}$ & \\
\hline Alive and eligible & $\begin{array}{c}-0.003 \\
(0.039)\end{array}$ & $\begin{array}{c}-0.008 \\
(0.039)\end{array}$ & $\begin{array}{c}0.030 \\
(0.026)\end{array}$ \\
\hline Alive and ineligible & $\begin{array}{c}0.019 \\
(0.052)\end{array}$ & $\begin{array}{c}0.104 \\
(0.069)\end{array}$ & $\begin{array}{c}0.082 \\
(0.058)\end{array}$ \\
\hline \multicolumn{4}{|l|}{ Fathers } \\
\hline Alive and never worked & $\begin{array}{c}0.072 \\
(0.068)\end{array}$ & $\begin{array}{c}0.075 \\
(0.067)\end{array}$ & \\
\hline Alive and eligible & $\begin{array}{c}-0.004 \\
(0.020)\end{array}$ & $\begin{array}{c}-0.004 \\
(0.020)\end{array}$ & $\begin{array}{c}-0.004 \\
(0.020)\end{array}$ \\
\hline Alive and ineligible & $\begin{array}{c}-0.003 \\
(0.029) \\
\end{array}$ & $\begin{array}{c}-0.021 \\
(0.037) \\
\end{array}$ & $\begin{array}{c}-0.001 \\
(0.038) \\
\end{array}$ \\
\hline \multicolumn{4}{|l|}{ Fathers in law } \\
\hline Alive and never worked & $\begin{array}{c}-0.073 \\
(0.078)\end{array}$ & $\begin{array}{c}-0.068 \\
(0.075)\end{array}$ & \\
\hline Alive and eligible & $\begin{array}{c}-0.003 \\
(0.020)\end{array}$ & $\begin{array}{c}-0.001 \\
(0.019)\end{array}$ & $\begin{array}{c}-0.001 \\
(0.019)\end{array}$ \\
\hline Alive and ineligible & $\begin{array}{c}-0.010 \\
(0.031)\end{array}$ & $\begin{array}{c}-0.015 \\
(0.051) \\
\end{array}$ & $\begin{array}{c}-0.013 \\
(0.055)\end{array}$ \\
\hline Grandparent's age (linear and squared) and education & Yes & Yes & Yes \\
\hline Woman's age (linear and squared) and education & Yes & Yes & Yes \\
\hline Partner's education and income & Yes & Yes & Yes \\
\hline Grandparent’s employment sector and type & Yes & Yes & Yes \\
\hline Municipality size & Yes & Yes & Yes \\
\hline Region $\times$ year fixed effects & Yes & Yes & Yes \\
\hline Observations & 8402 & 8402 & 8402 \\
\hline Mother alive eligible - Mother alive ineligible & $0.078 * *$ & 0.064 & $0.071^{* *}$ \\
\hline Employed women if mother alive ineligible & $59.25 \%$ & $55.53 \%$ & $40.47 \%$ \\
\hline
\end{tabular}

Note: The sample includes women aged 20-49, who have at least one child under 15 living in the household. Standard errors in parenthesis are bootstrapped only in column (1) and clustered by household, observations are weighted, and the omitted category for availability status is being dead. * $p$-value $<0.1, * * p$-value $<.05$, *** $p$-value $<.01$. 


\section{Table 8}

Effect of grandparental availability on the Employment of Women with Children under 15 - Heckman selection model

\begin{tabular}{|c|c|c|}
\hline Dep.var.: & $\begin{array}{c}\text { Child 0-14 (selection) } \\
\text { (1) }\end{array}$ & $\begin{array}{c}\text { Employment } \\
(2)\end{array}$ \\
\hline \multicolumn{3}{|l|}{ Mothers } \\
\hline Alive and never worked & $\begin{array}{c}0.047 \\
(0.066)\end{array}$ & $\begin{array}{c}0.026 \\
(0.025)\end{array}$ \\
\hline \multirow[t]{2}{*}{ Alive and eligible } & 0.143 & $0.086^{* *}$ \\
\hline & $(0.099)$ & $(0.044)$ \\
\hline \multirow[t]{2}{*}{ Alive and ineligible } & 0.045 & 0.009 \\
\hline & $(0.114)$ & $(0.049)$ \\
\hline \multicolumn{3}{|l|}{ Mothers-in-law } \\
\hline Alive and never worked & $\begin{array}{c}0.027 \\
(0.057)\end{array}$ & $\begin{array}{l}-0.073 \\
(0.077)\end{array}$ \\
\hline \multirow[t]{2}{*}{ Alive and eligible } & -0.006 & -0.004 \\
\hline & $(0.089)$ & $(0.020)$ \\
\hline \multirow[t]{2}{*}{ Alive and ineligible } & 0.067 & -0.008 \\
\hline & $(0.121)$ & $(0.033)$ \\
\hline \multirow{3}{*}{$\begin{array}{l}\text { Fathers } \\
\text { Alive and never worked }\end{array}$} & & \\
\hline & 0.047 & 0.073 \\
\hline & $(0.169)$ & $(0.071)$ \\
\hline \multirow[t]{2}{*}{ Alive and eligible } & 0.033 & -0.004 \\
\hline & $(0.049)$ & $(0.021)$ \\
\hline \multirow[t]{2}{*}{ Alive and ineligible } & -0.084 & -0.003 \\
\hline & $(0.085)$ & $(0.028)$ \\
\hline \multicolumn{3}{|l|}{ Fathers in law } \\
\hline \multirow[t]{2}{*}{ Alive and never worked } & 0.123 & 0.041 \\
\hline & $(0.173)$ & $(0.027)$ \\
\hline \multirow{2}{*}{ Alive and eligible } & 0.101 & -0.003 \\
\hline & $(0.048)$ & $(0.040)$ \\
\hline \multirow{2}{*}{ Alive and ineligible } & -0.109 & 0.019 \\
\hline & $(0.087)$ & $(0.052)$ \\
\hline \multirow[t]{2}{*}{ N. of spouse's non-cohabiting siblings alive } & $0.152^{* *}$ & - \\
\hline & $(0.061)$ & \\
\hline \multirow[t]{2}{*}{ Inverse Mill's Ratio } & - & -0.021 \\
\hline & & $(0.158)$ \\
\hline $\begin{array}{l}\text { Grandparent's age (linear and squared) and } \\
\text { education }\end{array}$ & Yes & Yes \\
\hline Woman's age (linear and squared) and education & Yes & Yes \\
\hline Partner's education and income & Yes & Yes \\
\hline Grandparent's employment sector and type & Yes & Yes \\
\hline Municipality size & Yes & Yes \\
\hline Region $\times$ year fixed effects & Yes & Yes \\
\hline Observations & 13441 & 8402 \\
\hline Mother alive eligible - Mother alive ineligible & 0.029 & $0.078^{* *}$ \\
\hline Mean for women with mother alive ineligible & $62.49 \%$ & $59.25 \%$ \\
\hline
\end{tabular}

Note: The sample includes women aged 20-49, who have at least one child under 15 living in the household. Standard errors in parenthesis are bootstrapped only in column (1) and clustered by household, observations are weighted, and the omitted category for availability status is being dead. Column (1) reports the coefficients of the probit selection equation. * $p$-value $<0.1$, $* * p$-value $<.05$, $* * * p$-value $<.01$. 


\begin{tabular}{|c|c|}
\hline \multicolumn{2}{|l|}{$\begin{array}{r}\text { APPENDIX } \\
\text { Table A1 }\end{array}$} \\
\hline Dep.var.: Actual years of contribution & (1) \\
\hline Male & $\begin{array}{c}5.210^{* * *} \\
0.062\end{array}$ \\
\hline Age & $\begin{array}{c}0.627^{* * *} \\
0.003\end{array}$ \\
\hline Education: None & ref \\
\hline Education: Primary & $\begin{array}{c}5.959 * * * \\
0.149\end{array}$ \\
\hline Education: Lower secondary & $\begin{array}{c}8.373^{* * *} \\
0.157\end{array}$ \\
\hline Education: Upper secondary and vocational & $\begin{array}{c}7.709 * * * \\
0.160\end{array}$ \\
\hline Education: Tertiary & $\begin{array}{c}5.535^{* * *} \\
0.181\end{array}$ \\
\hline Education: Post-tertiary & $\begin{array}{c}4.061^{* * *} \\
0.684\end{array}$ \\
\hline Sector: Agriculture & ref \\
\hline Sector: Industry & $\begin{array}{c}-0.817^{* * *} \\
0.193\end{array}$ \\
\hline Sector: Public & $\begin{array}{c}0.695^{* * *} \\
0.199\end{array}$ \\
\hline Sector: Others & $\begin{array}{c}-1.627 * * * \\
0.193\end{array}$ \\
\hline Sector: Not in the labor force & $\begin{array}{c}-4.590 * * * \\
0.192 \\
\end{array}$ \\
\hline Regions & Yes \\
\hline Years & Yes \\
\hline Observations & 74866 \\
\hline
\end{tabular}

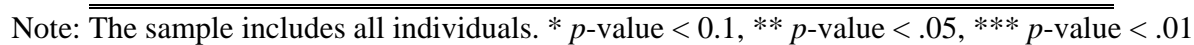

\section{Table A2}

Predicted Employment Rates under Different Scenarios

\begin{tabular}{ccccccccccc}
\hline \hline & \multicolumn{3}{c}{ Full sample (a) } & \multicolumn{3}{c}{ Children aged 0-5 (b) } & \multicolumn{3}{c}{ Only grandmothers with LFP (c) } \\
\cline { 2 - 10 } Year & Pre-Amato & Dini & Difference & Pre-Amato & Dini & Difference & Pre-Amato & Dini & Difference \\
\hline 1993 & 0.4735 & 0.4671 & 0.0064 & 0.4545 & 0.4312 & 0.0233 & 0.5801 & 0.5561 & 0.024 \\
1995 & 0.4906 & 0.4835 & 0.0071 & 0.4829 & 0.4561 & 0.0268 & 0.6032 & 0.5764 & 0.0268 \\
1998 & 0.5038 & 0.4958 & 0.008 & 0.5088 & 0.4789 & 0.0299 & 0.678 & 0.6503 & 0.0277 \\
2000 & 0.5102 & 0.5028 & 0.0074 & 0.5125 & 0.4891 & 0.0234 & 0.6631 & 0.6353 & 0.0278 \\
2002 & 0.5137 & 0.5064 & 0.0073 & 0.4974 & 0.4707 & 0.0267 & 0.6571 & 0.6306 & 0.0265 \\
2004 & 0.5377 & 0.5307 & 0.007 & 0.5264 & 0.5013 & 0.0251 & 0.6747 & 0.6502 & 0.0245 \\
2006 & 0.5676 & 0.5606 & 0.007 & 0.5823 & 0.5535 & 0.0288 & 0.6931 & 0.6802 & 0.0129 \\
\hline \hline
\end{tabular}

Note: The Table reports the employment rates of different samples of women computed under different set of rules on pension eligibility for their mothers. The Pre-Amato scenario is based on the assumption that in all years the eligibility rules are those that were in place until 1992 (i.e. before the Amato reform). The Dini scenario is based on the assumption that in all years the more restrictive rules set by the 1995 Dini reform apply to everyone. The column "Difference" shows the difference between the two scenarios. The three samples considered consist of all women with children aged 0-14 (a), all women with children aged 0-5 (b), and all women with children aged 0-14, whose mothers participated in the labor force (c). These employment probabilities are plotted in Figure 3. 